\title{
Competition between electron transfer and energy migration in self-assembled porphyrin triads
}

\author{
E.I. Zenkevich ${ }^{\mathrm{a}, *}$, A. Willert ${ }^{\mathrm{b}}$, S.M. Bachilo ${ }^{\mathrm{a}}$, U. Rempel ${ }^{\mathrm{b}}$, D.S. Kilin ${ }^{\mathrm{c}}$, A.M. Shulga ${ }^{\mathrm{a}}$, \\ C. von Borczyskowski ${ }^{\mathrm{b}}$ \\ ${ }^{a}$ Institute of Molecular and Atomic Physics, Belarus Academy of Science, F. Skaryna Avenue 70, 220072, Minsk, Belarus \\ ${ }^{\mathrm{b}}$ University of Technology Chemnitz, Reichenhainer Str. 70, 09107 Chemnitz, Germany \\ ${ }^{\mathrm{c}}$ Belarus State University, F. Skaryna Avenue 4, 220050, Minsk, Belarus
}

\begin{abstract}
The photoinduced electron transfer (ET) and the energy migration (EM) processes have been studied in liquid solutions and polymeric (PMMA) films for the triads consisting of the Zn-octaethylporphyrin chemical dimer (the energy and electron donor, D) and dipyridyl substituted tetrapyrrole extra-ligands (porphyrins, chlorin, tetrahydroporphyrin) as the acceptors, $A$. On the basis of the time correlated single photon counting technique and femtosecond pump-probe spectroscopy, it has been shown that $D$ fluorescence quenching with time constant ranging from 1.7 to $10 \mathrm{ps}$ is due to competing EM and ET processes from the dimer to $A$ 's. In addition, the fluorescence decay time shortening (by $\sim 1.3-1.6$ times in toluene at $293 \mathrm{~K}$ ) is observed for electron accepting extra-ligands in the triads. The acceptor fluorescence quenching is hard dependent on the mutual spatial arrangement of the triad subunits, but becomes stronger upon the solvent polarity increase (addition of acetone to toluene solutions) as well as the temperature lowering (from 278 to $221 \mathrm{~K}$ ). The possible reasons and mechanisms of the non-radiative deactivation of locally excited $\mathrm{S}_{1}$-states in the triads are discussed taking into account a close lying charge-separated state. The obtained experimental data are analyzed using the reduced density matrix formalism in the frame of Haken-Strobl-Reineker approach. This model includes EM and ET processes as well as the dephasing of coherence between the excited electronic states of the triad. (C) 2001 Elsevier Science B.V. All rights reserved.
\end{abstract}

Keywords: Fluorescence quenching; Donor-acceptor interactions; Electron and energy transfer; Porphyrin supramolecular complexes; Reduced density matrix formalism; Coherence dephasing

\section{Introduction}

At present, on the basis of X-ray data, ps-fs time-resolved technique and single molecule spectroscopy with confocal microscopy, the detailed structural organisation and the energy relaxation dynamics of photosynthetic objects in vivo have been evaluated [1-5]. For plants and photosynthetic bacteria, it is well documented that the main primary photoevents occur in two energetically and structurally coupled pigment systems, that is in lightharvesting pigment-protein antenna complexes and in the photochemical reaction center (RC). Sun light is initially absorbed by light-harvesting pigment-protein antenna complexes which serve to carry out very fast and efficient light energy collection and transfer into the photochemical RC. Then, in the excited photosynthetic RC the energy of

\footnotetext{
${ }^{*}$ Corresponding author. Tel.: +375-172-841-563; fax: +375-172-840030 .

E-mail address: zenkev@imaph.bas-net.by (E.I. Zenkevich).
}

excited states is converted into a stable transmembrane charge separation through a sequence of electron transfer reactions. Native RC is highly optimised system where small changes of the energy level may cause the essential reduction in the efficiency. The light-induced charge separation realised in the $\mathrm{RC}$ is one of the most important photochemical reactions known.

Nevertheless, complicated excitonic interactions among antenna pigments may lead to the variation of excitonic states, which in the combination with a certain degree of disorder seems to be rather difficult for the detailed interpretation of the observed heterogeneous spectral-kinetic behaviour. In RC, the ET first step between the locally excited "special pair" (bacteriochlorophyll dimer) and the intermediate acceptor (bacteriopheophytin) is known to occur within 2-4 ps, followed by the subsequent ET second step within $\sim 200$ ps to the distant $(R=13-14 \AA)$ quinone [6]. All these ET processes are characterised by nearly $100 \%$ quantum efficiency, and the photoinitiated charge separation in vivo exhibits the activationless be- 
haviour being high effective in the solid state at liquid helium temperatures [6,7]. At the same time, however, some details of the distant ET processes remain non-understood yet. For instance, some of them are spectro-structural correlations, the role of pigment-protein interactions, the relatively weak temperature dependence and high efficiency of charge separation, and one-branch ET direction.

As neither the molecular photoprocesses mentioned above nor more complex light-induced functions such as photoswitching of on/off receptor donor-acceptor ability is achieved in single molecules, but requires significant communication between interacting subunits, supramolecular assemblies are truly relevant biomimetic models for the fundamental energy and charge storage strategies observed in physiological photosynthetic systems. From this point of view, the preparation of model multimolecular assemblies with functional properties to mimic important features of EM and ET photosynthetic events or to gain some insight into the principal possibilities of molecular electronics is one of the most popular tendencies of supramolecular photochemistry [8-10]. At the moment, supramolecular photochemistry is a highly interdisciplinary field of science covering the chemical, physical, and biological features of chemical species held together and structurally organized by means of intermolecular non-covalent binding interactions. Correspondingly, the hope of the future is that multimolecular aggregates of nanometre dimensions can be utilised in molecular electronics to provide the elementary active units of electronic systems with extremely high component density. On the basis of multiporphyrin moieties, various functional molecular nanodevices have recently been engineering and prepared: optoelectronic gates, photoinduced picosecond molecular switches, fluorescence sensors, photonic wires (see references in Ref. [11]).

Stimulated by earlier and recent biophysical investigations, the majority of model supramolecular porphyrin-type arrays have been used quite intensively in order to better understand factors and mechanisms which control the efficiency and directionality of the EM and ET reactions taking place without diffusional limitations [12-17]. Key studies of these complex systems currently focus on the formation of various multimolecular arrays, the evaluation of their structural parameters, and on the detailed analysis of electronic energy migration and vectorial electron transfer.

The formation of a variety of conformational restricted, structurally and energetically well-defined models is based presumably on two principally different approaches. One way of the biomimetic chemistry is a popular methodology using the covalent linkage between supposedly essential components [18-33]. It has been shown that the intracomplex ET may take place in a wide time-scale up to femtosecond region. ET rate constants depend on the energy of $D$ locally excited $\mathrm{S}_{1}$ - and $\mathrm{T}_{1}$-states, redox properties of interacting $D-A$ components, their mutual geometry and $D-A$ intercenter distance as well as on the solvent temperature and polarity. In addition, the energy, geometry and nature of the spacer determine the main ET pathways (through-bond or through-space [22,34]). The effective charge separation over distances up to $\sim 20-26$ $\AA$ and the formation of a long-living radical ion pair have been realized. In only few successful cases, it has been shown that ET remains still effective within several picoseconds at $77-10 \mathrm{~K}$ in model porphyrin- $A$ systems $[13,18,19]$ and between porphyrin subunits in artificial triads [17]. It has been demonstrated that non-radiative EM processes in multiporphyrin assemblies are distance and orientation dependent $[21,23-25,30,32]$. Two major mechanisms for EM with participation of excited $\mathrm{S}_{1^{-}}$and $\mathrm{T}_{1^{-}}$ states have been identified in the systems of various complexity, that is long-distant inductive-resonant mechanism without the direct contact of $D-A$ components [35], and exchange-resonant mechanism realized via spatial overlap of interacting subunits [36]. In addition, the enhanced electronic coupling between porphyrins [37] or monopole effects on electronic excitation interactions [38] may be responsible for the fast EM in covalently linked multicomponent systems.

The other approach in the construction of biologically significant structures is based on non-covalent interactions of various nature (electrostatic interactions [39], hydrogen bonding [40,41], co-ordination interactions [42]). This way provides a synthetically very simple route to a wide variation of both qualitative and quantitative composition of supramolecular systems. Nevertheless, in some cases such arrays are not highly stable and characterised by flexible structure.

A new strategy for the construction of functional supramolecular assemblies generally proposed firstly by Lehn [43] is based on the combination of these two principally different approaches. Following these ideas, we realized a simple and yet potentially versatile strategy for fabricating highly organized multimolecular tetrapyrrole assemblies in non-polar or small polar solutions as well as in polymeric films [16,17,44-48].

At the first stage, it includes the design and synthesis of intermediate molecular blocks such as Zn-porphyrin or $Z n$-chlorin chemical dimers or trimers where $\pi$-conjugated macrocycles are covalently linked via spacers of various nature $\left(-\mathrm{CH}_{2}-\mathrm{CH}_{2}-\right.$ bond or phenyl ring in mesoposition). Additionally, different types of electron acceptors (quinone, anthraquinone, pyromellitimide, $\mathrm{NO}_{2}$-group) may be covalently linked to these dimers by flexible or rigid spacers using the techniques of organic chemistry. At the second stage, newly prepared molecular blocks may be self-assembled with pyridyl containing porphyrin or chlorin extra-ligands via non-covalent binding interactions (twofold extra-ligation effect with "key-hole" principle). It was shown that the matching geometry between $\mathrm{N}$ atoms in pyridyl containing extra-ligands and $\mathrm{Zn}-\mathrm{Zn}$ distance in the dimers and trimers plays the essential role in the formation 
of triads and pentads with relatively well defined conformational rigidity. The corresponding mutual orientations and intercenter distances could be obtained using the optimised structures of the systems (HyperChem software, release 4, methods AM1 and PM3). In the result, we have succeeded to form distinct arrays of variable structure with a controlled number of electronically interacting chromophores. Spectral, photophysical and thermodynamic properties have been investigated for such complexes of various geometry and composition. The alternative principles of Zn-chlorin aggregates self-assembling coupled with the covalent link with the bacteriochlorin molecule have been proposed and realized recently by the other international scientific group [49].

Primary photoprocesses in photosynthesis involve the electronic excitation energy migration among antenna chlorophylls followed by EM process from antenna to the RC "special pair" [1-5]. Interestingly, that in RC the initial photoinduced ET event occurs also between tetrapyrrole chromophores (from chlorophyll "special pair" to pheophytine or chlorophyll [6]). In this respect, it should be mentioned that while EM processes in artificial multiporphyrin systems have been widely investigated [21,23$25,30,32,37,38]$, the number of research groups which have undertaken studies of interporphyrin ET is relatively smaller [17,22,31,50-53]. Herein, we report the results showing the interplay between EM and ET in self-assembled triads of tetrapyrrole compounds where these processes determine the dominant pathways in the non-radiative deactivation of the locally excited states of interacting subunits.

\section{Experimental}

Self-assembled triads of various but controlable geometry (Fig. 1) were formed (using the extra-ligation effect [44,45]) from a covalently linked Zn-octaethylporphyrin dimer, $(\mathrm{ZnOEP})_{2} \mathrm{Ph}$ as $\mathrm{D}$ of the energy and electron, and dipyridyl-substituted tetrapyrrole free bases [porphyrin $\left(\mathrm{H}_{2} \mathrm{P}\right)$, chlorin $\left(\mathrm{H}_{2} \mathrm{Chl}\right)$, tetrahydroporphyrin $\left.\left(\mathrm{H}_{2} \mathrm{THP}\right)\right]$ as corresponding energy/electron $A$ 's. The synthesis, identification and purification of the dimer $(\mathrm{ZnOEP})_{2} \mathrm{Ph}$, 1,4-bis\{[zinc(II)] 5-(2,3,7,8,12,13,17,18-octaethylporphyrinyl)] benzene and corresponding monomeric extraligands have been described in our earlier papers $[17,44,45]$.

The triads were formed during a successive titration of the dimer $(\mathrm{ZnOEP})_{2} \mathrm{Ph}$ solution (concentration of $1 \times$ $10^{-6}-4 \times 10^{-6} \mathrm{M}$ ) with an extra-ligand solution (concentration of $\left.0.3 \times 10^{-4}-2 \times 10^{-4} \mathrm{M}\right)$. Absorption and fluorescence (excited at the isosbestic point observed in the absorption) spectra have been measured after each step of the titration procedure and then have been used for the calculation of the complexation constants (the method was described in Ref. [44]). It is seen from Table 1 that all triadic complexes are characterised by high complexation constants $K_{\mathrm{C}} \sim 10^{6}-10^{7} \mathrm{M}^{-1}$ that is by approximately two orders of magnitude higher with respect to those found for dipyridinated complexes of the dimer $(\mathrm{ZnOEP})_{2} \mathrm{Ph}$.

High $K_{\mathrm{C}}$ values for triads are explained by two-point co-ordination interaction between two nitrogens of extra-ligand pyridyl rings and two central $\mathrm{Zn}$ ions of the dimer. Nevertheless in all cases $K_{\mathrm{C}}(\mathrm{m} \wedge \mathrm{Pyr})_{2}>K_{\mathrm{C}}(\mathrm{m}-\mathrm{Pyr})_{2}$, $K_{\mathrm{C}}\left(\mathrm{p}^{\wedge} \mathrm{Pyr}\right)_{2}$ due to steric hindrance effects $[44,45]$. In rigid

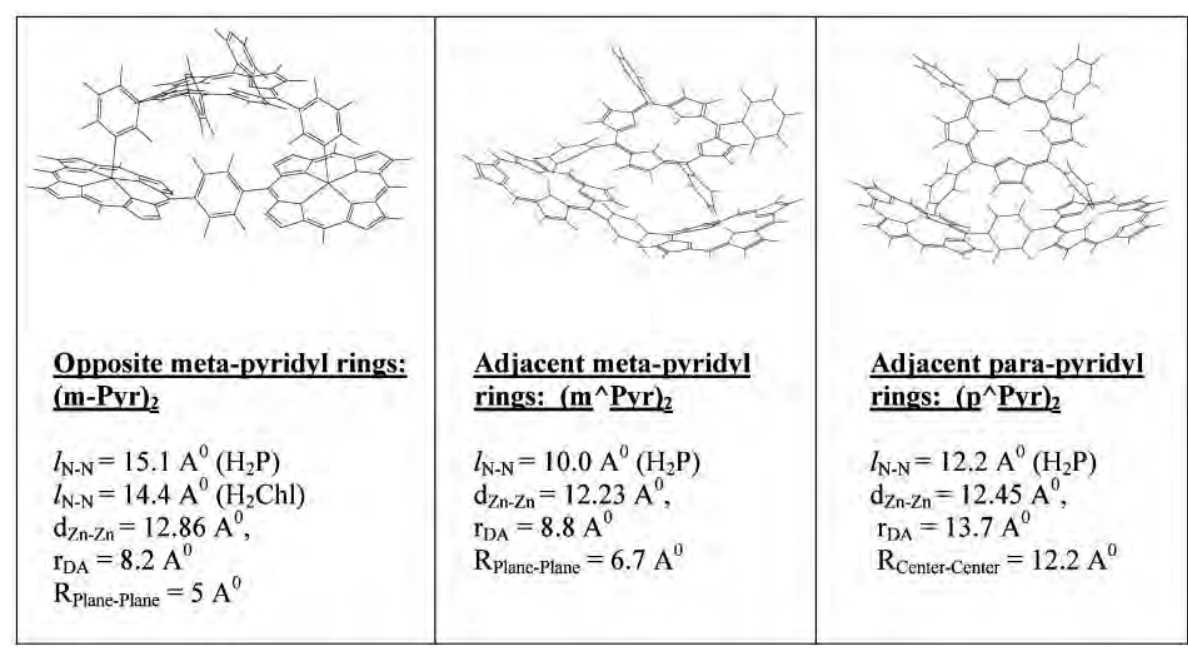

Fig. 1. Mutual arrangement of interacting subunits and geometrical parameters for optimised triads containing chemical dimer $(\mathrm{ZnOEP})_{2} \mathrm{Ph}$ and various extra-ligands (HyperChem software package, release 4, semiempirical methods AM1 and PM3). The corresponding acceptors were used: (i) porphyrin, $\mathrm{H}_{2} \mathrm{P}$ containing two meso-phenyls and two meso-pyridyl rings with different positions of both pyridyl rings (opposite and adjacent) and pyridyl nitrogens $\mathrm{N}$ (meta and para): opposite meta-pyridyl rings $-\mathrm{H}_{2} \mathrm{P}(\mathrm{m}-\mathrm{Pyr})_{2}$-(iso- $\left.\mathrm{PrPh}\right)_{2}$, adjacent meta-pyridyl rings- $\mathrm{H}_{2} \mathrm{P}\left(\mathrm{m}^{\wedge} \mathrm{Pyr}\right)_{2}$-(iso- $\left.\mathrm{PrPh}\right)_{2}$ and adjacent para-pyridyl rings $-\mathrm{H}_{2} \mathrm{P}\left(\mathrm{p}^{\wedge} \mathrm{Pyr}\right)_{2}$; (ii) chlorin with opposite meta-pyridyl rings- $\mathrm{H}_{2} \mathrm{Chl}(\mathrm{m}-\mathrm{Pyr})_{2}$; (iii) tetrahydroporphyrin with opposite meta-pyridyl rings- THP(m-Pyr $)_{2} . r_{\mathrm{DA}}$ denotes the intercenter distance, $l_{\mathrm{N}-\mathrm{N}}$ corresponds to the distance between two extra-ligand nitrogens interacting with two central $\mathrm{Zn}$ ions of the dimer, $d_{\mathrm{Zn}-\mathrm{Zn}}$ is the distance between two central $\mathrm{Zn}$ ions of the dimer in the triad, $R_{\text {Plane-Plane }}$ and $R_{\text {Center-Center }}$ are interplane and intercenter distances correspondingly between dimer and extra-ligand. 
Table 1

Complexation constants, $K_{\mathrm{C}}$ for triads containing chemical dimer $(\mathrm{ZnOEP})_{2} \mathrm{Ph}$ and various extra-ligands (toluene, $293 \mathrm{~K}$ )

\begin{tabular}{lll}
\hline No. & Triad & $K_{\mathrm{C}}\left(\mathrm{M}^{-1}\right)$ \\
\hline 1 & $(\mathrm{ZnOEP})_{2} \mathrm{Ph} \otimes \mathrm{H}_{2} \mathrm{P}\left(\mathrm{m}^{\wedge} \mathrm{Pyr}\right)_{2}$-(iso-PrPh $)_{2}$ & $1.7 \times 10^{7}$ \\
2 & $(\mathrm{ZnOEP})_{2} \mathrm{Ph} \otimes \mathrm{H}_{2} \mathrm{P}\left(\mathrm{p}^{\wedge} \mathrm{Pyr}\right)_{2}$ & $5.0 \times 10^{6}$ \\
3 & $(\mathrm{ZnOEP})_{2} \mathrm{Ph} \otimes \mathrm{H}_{2} \mathrm{P}(\mathrm{m}-\mathrm{Pyr})_{2}$-(iso-PrPh $)_{2}$ & $1.1 \times 10^{6}$ \\
4 & $(\mathrm{ZnOEP})_{2} \mathrm{Ph} \otimes \mathrm{H}_{2} \mathrm{Chl}(\mathrm{m}-\mathrm{Pyr})_{2}$ & $1.7 \times 10^{6}$ \\
5 & $(\mathrm{ZnOEP})_{2} \mathrm{Ph} \otimes \mathrm{H}_{2} \mathrm{THP}(\mathrm{m}-\mathrm{Pyr})_{2}$ & $3.0 \times 10^{6}$ \\
\hline
\end{tabular}

polymethylmetacrylate films, the values of the corresponding complexation constants are a little bit higher but the same tendency is found for various extra-ligands.

Toluene, acetone, methylcyclohexane (Aldrich HPLC grade) and PMMA have been used as solvents.

The steady-state fluorescence and excitation spectra were recorded on a Shimadzu RF-5001PC spectrofluorimeter and absorption spectra on a Shimadzu UV-3101PC spectrophotometer.

In order to analyse multicomponent kinetics, the time correlated single photon counting (TCSPC) experiments were performed. For excitation, a vertical polarised dye laser (Spectra $\mathrm{Ar}^{+}$-Laser Mod. 171/Dye-Laser Mod. 343) with a repetition-rate of $4 \mathrm{MHz}$ and pulses of $15 \mathrm{ps}$ FWHM was used. The fluorescence was detected under the magic angle $\left(54.7^{\circ}\right)$ through a minimonochromator by a micro-channel-plate. The system response was $\Delta t_{1 / 2}=75$ ps. To obtain amplitude spectra for every sample the detection was done multiple at 12 different wavelengths covering a range from 570 to $740 \mathrm{~nm}$. The convolution was done with three times for each data-set using global analysis in a commercial software program with the minimisation of chi-square values $\left(\chi^{2}\right)$.

For the pump-probe experiments, a regenerative amplifier system (Quantronix 4800 Series, Ti: Sa regenerative amplifier, $1 \mathrm{kHz}$ ) driven by a Coherent Mira 900B Ti/Sa

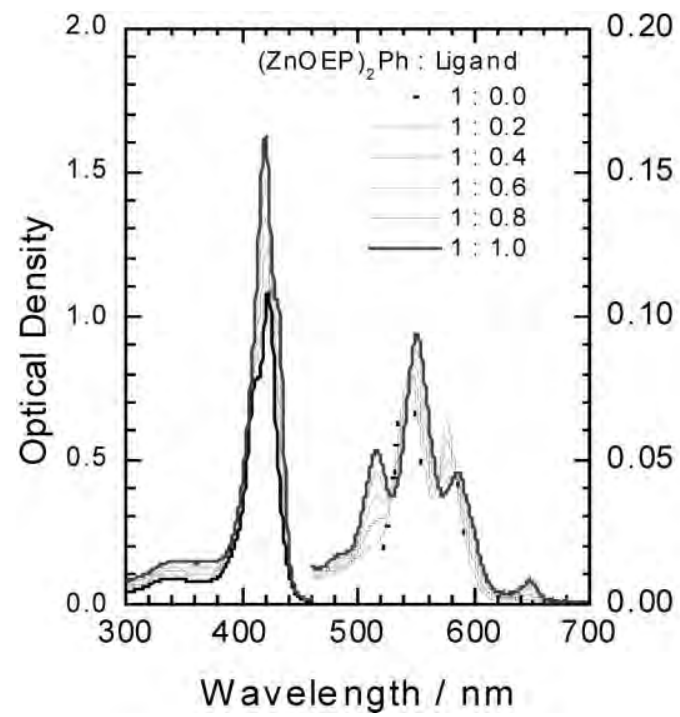

laser was used to generate the pump wavelength in an optic parametric amplifier (TOPAS). The wavelength could be tuned from 400 to $800 \mathrm{~nm}$. The probe wavelength was generated in a quartz-plate as a supercontinuum ranging from $450 \mathrm{~nm}$ to the near IR. Pump and probe-beam transmit the sample under the magic angle. The experimental response was $\Delta t_{1 / 2} \sim 280$ fs. The kinetics were deconvoluted using a multiexponential fit. The details of the experimental setup have been described in our earlier paper [17]. Time-resolved TCSPC and pump-probe experiments were performed in a homemade quartz cell equipped with a mini-motor for the solution circulation (volume of 9 $\mathrm{ml}$ ) in order to avoid artefacts caused by a possible photodecomposition of the compounds. The possible manifestation of multiphoton effects during fs pump-probe measurements has been tested upon the variation of the energy of the pumping pulse. The spinning frequency was chosen to have a fresh excitation volume for each pump pulse (i.e. every $1 \mathrm{~ms}$ ) as well as the whole relaxation of excited states took place before the following exciting pulse.

For temperature dependent measurements, a homemade cryostat was used equipped with the temperature controller ITC502 (Oxford Instruments).

\section{Results and discussion}

\subsection{Steady-state and time-resolved data}

We already reported and discussed steady-state absorption and fluorescence spectra, which definitely proof the ability of the porphyrin chemical dimers and extra-ligands to form 1:1 self-assembled triads with the high complexation constant in non-polar solvents at 293 K [44]. Spectral transformations typical for all systems being studied are shown in Fig. 2. As a result, upon the triad formation the

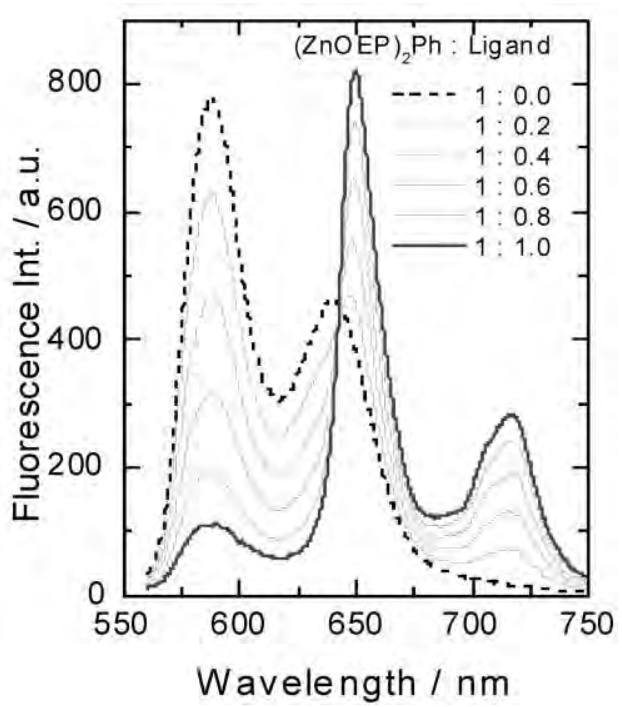

Fig. 2. Absorption and fluorescence $\left(\lambda_{\text {ex }}=546 \mathrm{~nm}\right.$, isosbestic point) spectra transformations upon the triad $(\mathrm{ZnOEP})_{2} \mathrm{Ph} \otimes \mathrm{H}_{2} \mathrm{P}\left(\mathrm{m}^{\wedge} \mathrm{Pyr}\right)_{2}-(\text { iso- } \mathrm{PrPh})_{2}$ formation (toluene, $293 \mathrm{~K}$ ). The dimer:ligand molar ratio varies from $x=1: 0$ to $1: 1$. 
red shift of the dimer long wavelength absorption $Q_{x}(0,0)$ band is observed accompanied by the dimer fluorescence quenching and the relative rise of the extra-ligand emission. Our previous results show that absorption spectra of the triads are essentially a linear combination of the corresponding dipyridinated dimer $(\mathrm{ZnOEP})_{2} \mathrm{Ph}$ and extraligand, with only small differences in wavelength maxima and band shapes. It means that the interaction between the two subunits is weak and they retain their individual identities. Taking into account $K_{\mathrm{C}}$ values presented in Table 1, one may found that at ratio $1: 1,85 \%$ of the interacting molecules are bound in triads for $\mathrm{H}_{2} \mathrm{P}\left(\mathrm{m}^{\wedge} \mathrm{Pyr}\right)_{2}-$ (iso- $\mathrm{PrPh})_{2}$, while for the ligand $\mathrm{H}_{2} \mathrm{P}(\mathrm{m}-\mathrm{Pyr})_{2}$-(iso- $\left.\mathrm{PrPh}\right)_{2}$ with smaller complexation constant $52 \%$ of the molecules are bond (at total concentration of each component $2 \times$ $10^{-6} \mathrm{M}$ ). These estimations have been used upon the analysis of TCSPC data.

As far as there is a good spectral overlap between the dimer fluorescence spectrum and extra-ligands absorption bands it seems to be reasonable to connect the ( $\mathrm{ZnOEP})_{2} \mathrm{Ph}$ emission quenching with EM processes in the triads. Quite obviously EM from the dimer to an extra-ligand has to lead to the sensitised emission of the last. For example, Fig. 3 shows that the fluorescence excitation spectrum of the triad $(\mathrm{ZnOEP})_{2} \mathrm{Ph} \otimes \mathrm{H}_{2} \mathrm{P}\left(\mathrm{m}^{\wedge} \mathrm{Pyr}\right)_{2}$-(iso- $\left.\mathrm{PrPh}\right)_{2}$ in pure toluene (monitored at $720 \mathrm{~nm}$ where the majority of the emission comes from the extra-ligand) contains 549 and $587 \mathrm{~nm}$ bands belonging in the absorption to the dimer. On the base of the comparison of absorption and fluorescence excitation spectra for triads containing $\mathrm{H}_{2} \mathrm{P}, \mathrm{H}_{2} \mathrm{Chl}$ and $\mathrm{H}_{2} \mathrm{HP}$ extra-ligands the singlet-singlet EM efficiency was estimated to be $\Phi=70-80 \%$ in pure toluene.
For porphyrin chemical dimers with various structures and properties of coupled halves, we have shown that at intercenter distances $r_{\mathrm{DA}}=10.6-12.3 \AA$ the Forster theory of inductive resonance is still applicable to weakly interacting porphyrin chromophores, and theoretical calculations of EM parameters are in a reasonable agreement with experimental estimations [26,32]. The reason of that may be explained by the following way. Really, intercenter distances in the dimers are comparable with molecular dimensions (porphyrin radius is estimated by the value of $r=5-5.5 \AA[17,48]$. At the same time, molar decimal extinction coefficient values of $\varepsilon_{\mathrm{Q}} \approx 4000-50,000 \mathrm{M}^{-1}$ $\mathrm{cm}^{-1}$ for porphyrin $Q$-band correspond to the effective length of interacting dipoles $|\mu| \leq 1-2.7 \AA$ [32]. It means that $|\mu| \ll r_{\mathrm{DA}}$, and the point dipole-dipole approximation is valid. Correspondingly, we apt to believe that in porphyrin triads ( $r_{\mathrm{DA}}=8.2-13.7 \AA$, see Fig. 1$)$ we may apply the inductive-resonant model for the quantitative description of the non-radiative electron-vibrational energy transfer. A model based on the enhanced electronic coupling between porphyrins [37] or monopole effects on electronic excitation interactions [38] will be the subject of our further considerations.

On the basis of optimised geometry of the triads (HyperChem software package, release 4, semiempirical methods AM1 and PM3, see Fig. 1) and Forster inductiveresonant model [35], we calculated the corresponding orientational factors $k^{2}=\left[\cos \left(\mu_{\mathrm{D}}, \mu_{\mathrm{A}}\right)-3 \cos \left(\mu_{\mathrm{D}}, r_{\mathrm{DA}}\right)\right.$ $\left.\cos \left(\mu_{\mathrm{A}}, r_{\mathrm{DA}}\right)\right]^{2}=0.47 \div 0.75$, where $\left(\mu_{\mathrm{D}}, \mu_{\mathrm{A}}\right)$ is the angle between transition dipole moment vectors of the $D$ and $A$ subunits, $\left(\mu_{\mathrm{D}}, r_{\mathrm{DA}}\right)$ and $\left(\mu_{\mathrm{A}}, r_{\mathrm{DA}}\right)$ denote the angles between the dipole vectors of $D$ and $A$ and the

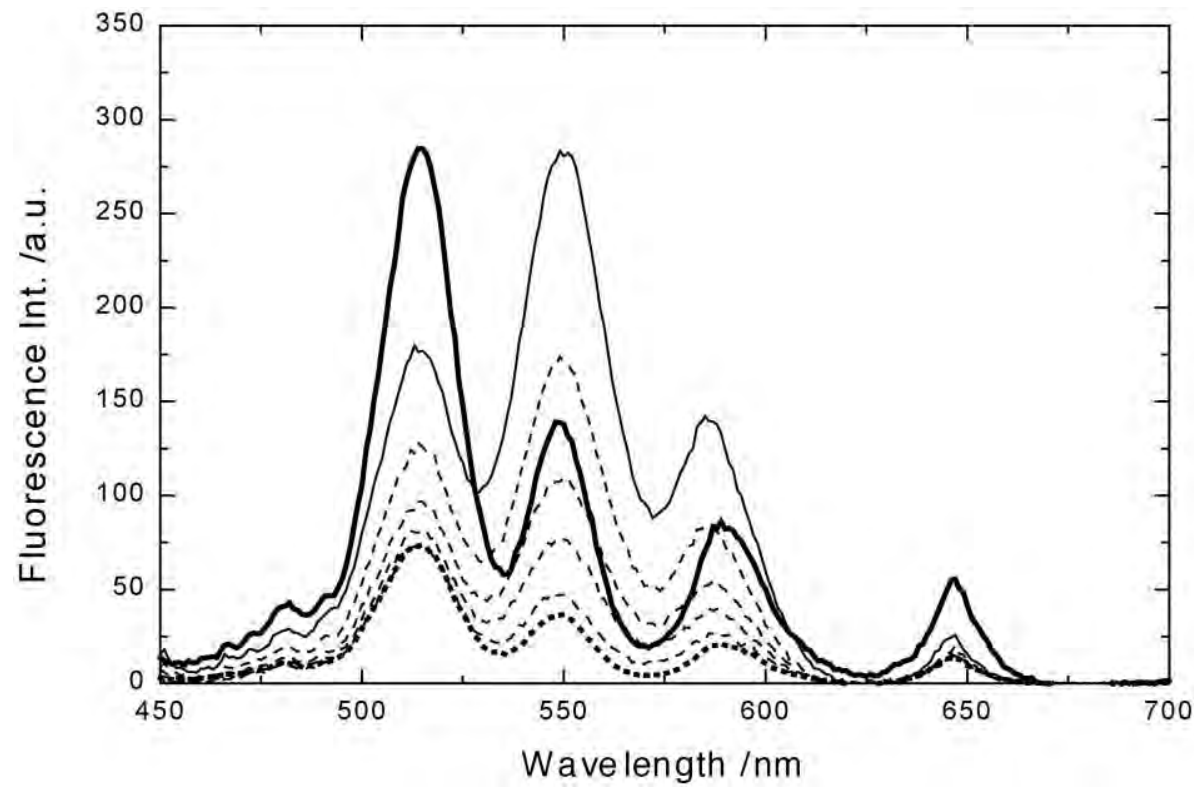

Fig. 3. Corrected fluorescence excitation spectra of the triad $(\mathrm{ZnOEP})_{2} \mathrm{Ph} \otimes \mathrm{H}_{2} \mathrm{P}\left(\mathrm{m}^{\wedge} \mathrm{Pyr}\right)_{2}$-(iso- $\left.\mathrm{PrPh}\right)_{2}\left(x=0.92, c_{\mathrm{D} 0}=2.6 \times 10^{-6}, \lambda_{\mathrm{em}}=720 \mathrm{~nm}\right)$ in toluene plus 0 (thin solid line), 3, 6, 9, 17 vol.\% of acetone (thin dashed lines). $\mathrm{H}_{2} \mathrm{P}$ in toluene at same concentration as in triad (bold line). $\mathrm{H}_{2} \mathrm{P}$ excitation spectrum divided by $3.83(\cdots \cdots \cdot \cdot)$. 
direction $D \rightarrow A$, respectively. Then taking into account experimental fluorescence parameters of the dimer $(\mathrm{ZnOEP})_{2} \mathrm{Ph}, D$ (lifetime $\tau_{\mathrm{S}}=1.15 \mathrm{~ns}$, quantum yield $\varphi_{\mathrm{S}}=0.012$ for dipyridinated complex, toluene, $\left.293 \mathrm{~K}\right)$ and absorption spectra of extra-ligands, $A$ 's, we calculated numerically spectral overlap integrals

$$
\begin{aligned}
J & =\int_{0}^{\infty} f_{\mathrm{D}}(\nu) \times \varepsilon_{\mathrm{A}}(\nu) \frac{\mathrm{d} \nu}{\nu^{4}} \\
& =1.2 \times 10^{-14}-5.9 \times 10^{-14} \mathrm{~cm}^{-6} \mathrm{M}^{-1} .
\end{aligned}
$$

Finally, critical transfer distances were estimated to be $R_{0}^{\text {theor }}=16.8 \div 17.2 \AA$. When applying this model to the triads, we assume that, besides EM process, there are no pathways for depopulating $S_{1}$-state of the dimer other than the radiative decay and the intersystem crossing (internal conversion is neglected). Correspondingly, for the systems under consideration theoretical values of EM rate constants $\left[k_{\mathrm{EM}}=\left(1 / \tau_{\mathrm{S}}\right)\left(R_{0}^{\text {theor }} / r_{\mathrm{DA}}\right)^{6}\right]$ have to be in the range of $k_{\mathrm{EM}}=6.7 \times 10^{10}-7.5 \times 10^{10} \mathrm{~s}^{-1}$. It means that the $\mathrm{S}_{1}$ state lifetime of the dimer has to be shorten to values of $15-13$ ps.

However, experimental femtosecond pump-probe findings obtained for the triads do not coincide with the theoretical estimations. For instance, the main spectral features of time resolved spectra for the triad $(\mathrm{ZnOEP})_{2}$ $\mathrm{Ph} \otimes \mathrm{H}_{2} \mathrm{P}\left(\mathrm{m}^{\wedge} \mathrm{Pyr}\right)_{2}$-(iso- $\left.\mathrm{PrPh}\right)_{2} \quad$ (discussed in details in our previous paper [17]) are formed by bleaching of $\mathrm{H}_{2} \mathrm{P} Q$-bands at 515,550 and $580 \mathrm{~nm}$ and the absorption band at $670 \mathrm{~nm}$ usually ascribed to the Zn-porphyrin cation. So, the formation of charge transfer (CT) states is clearly detected. From the time evolution of transients, it is seen (Fig. 4) that the increase of $\mathrm{H}_{2} \mathrm{P}$ ground state bleaching at $510 \mathrm{~nm}$ is observed after an immediate rise at time zero. The decay was fitted with the time constant $1.7 \pm 0.1$ ps. The dynamics of the absorption at $680 \mathrm{~nm}$ are quite complex exhibiting an immediate rise which is followed by a decay with $1.7 \mathrm{ps}$ and a slower rise of $60 \mathrm{ps}$. As on the time scale accessible to our delay line $(\approx 4.5 \mathrm{~ns})$ almost no further changes in $\Delta \mathrm{OD}$ after a few ps could be observed. The spectra taken this way at long delay are typical of $\mathrm{H}_{2} \mathrm{P}$ ground state bleaching and an additional broad absorption may be attributed to both the singlet and the triplet excited states of $\mathrm{H}_{2} \mathrm{P}$ [54]. These results indicate clearly that the non-radiative relaxation of the dimer $\mathrm{S}_{1}$ state in the triads takes place within 1.7 ps that is essentially faster than 13-15 ps. This conclusion coincides with our earlier data $[16,47]$. The experimental value of $k_{\mathrm{EM}}=$ $2.9 \times 10^{11} \mathrm{~s}^{-1}\left(\tau_{\mathrm{S}}=3.5 \mathrm{ps}\right)$ was obtained for $\mathrm{ZnP}-\mathrm{H}_{2} \mathrm{PF}$ dimer with the distances $r_{\mathrm{DA}}$ of the same order [37]. In the later case, the enhanced (with respect to Forster model calculations) excited-state energy-transfer rates have been attributed to enhanced electronic coupling between the porphyrin constituents across the p-phenylene linker (through-bond mechanism) with a possible influence of a ground-state hole/electron hopping.

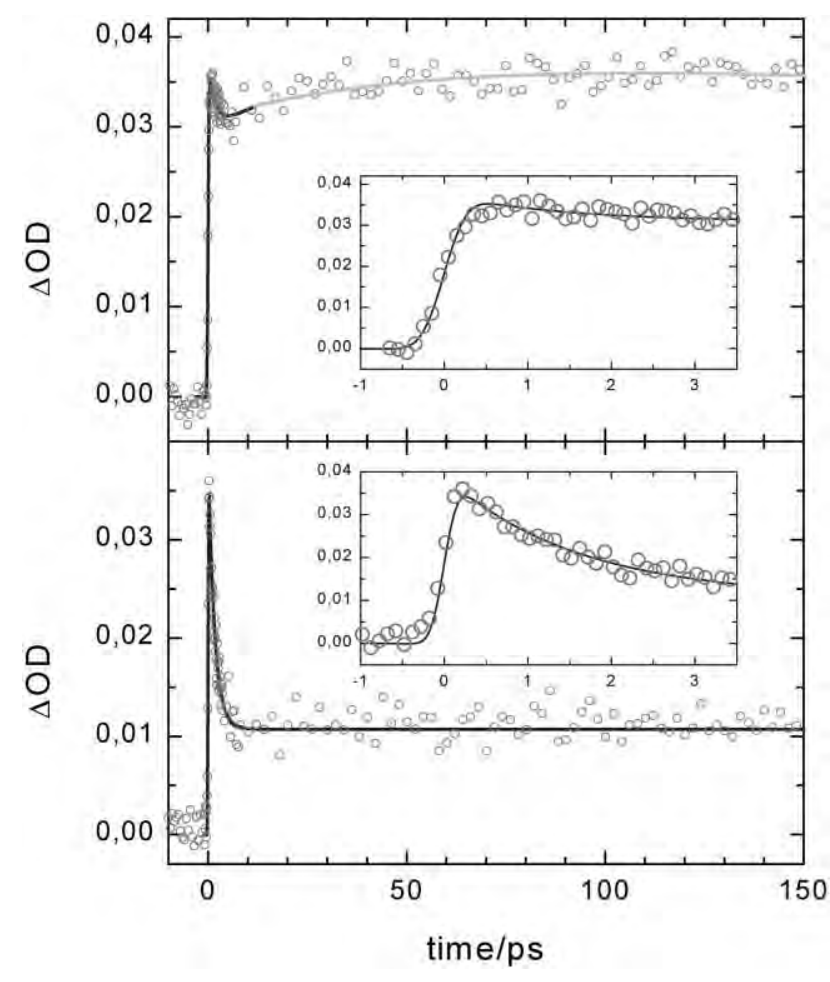

Fig. 4. Time evolution of transient absorbance of a toluene solution of the triad $(\mathrm{ZnOEP})_{2} \mathrm{Ph} \otimes \mathrm{H}_{2} \mathrm{P}\left(\mathrm{m}^{\wedge} \mathrm{Pyr}\right)_{2}$-(iso- $\left.\mathrm{PrPh}\right)_{2}$ pumped at $555 \mathrm{~nm}$ and probed at 670 (top) and 510 (bottom) nm.

The key point to be derived from the above results is that in the triads containing $(\mathrm{ZnOEP})_{2} \mathrm{Ph}$ and $\mathrm{H}_{2} \mathrm{P}, \mathrm{H}_{2} \mathrm{Chl}$ and $\mathrm{H}_{2} \mathrm{HP}$ extra-ligands, the non-radiative relaxation of singlet excited states of both subunits may be due to not only EM process but should include photoinduced electron transfer. Hence, in order to analyse the interplay between these two processes in the systems under consideration, one should take into account that at the constant geometry of the triad EM is hard dependent on the temperature (77-293 K) and polarity of the solvent [35] while rate constants of the non-adiabatic ET are sensitive to these parameters and are dependent on redox properties of interacting $D-A$ reactants [55].

\subsection{Influence of solvent polarity and temperature}

The corresponding "polarity-temperature" experiments have been carried out for all triads in toluene and PMMA films using both steady-state and time-resolved methods. For clarity, the main results and conclusions we shall present for the triad $(\mathrm{ZnOEP})_{2} \mathrm{Ph} \otimes \mathrm{H}_{2} \mathrm{P}\left(\mathrm{m}^{\wedge} \mathrm{Pyr}\right)_{2}$-(iso$\mathrm{PrPh})_{2}$. Fig. 5 (Inset) shows that upon excitation of the triad at $650 \mathrm{~nm}$ (where only $\mathrm{H}_{2} \mathrm{P}$ subunit absorbs) in pure toluene, the extra-ligand fluorescence quantum efficiency is reduced with respect to that for the pure $\mathrm{H}_{2} \mathrm{P}$ at the same conditions. In order to test whether charge transfer processes may be involved in this quenching which are expected to depend on the dielectric constant of the sol- 


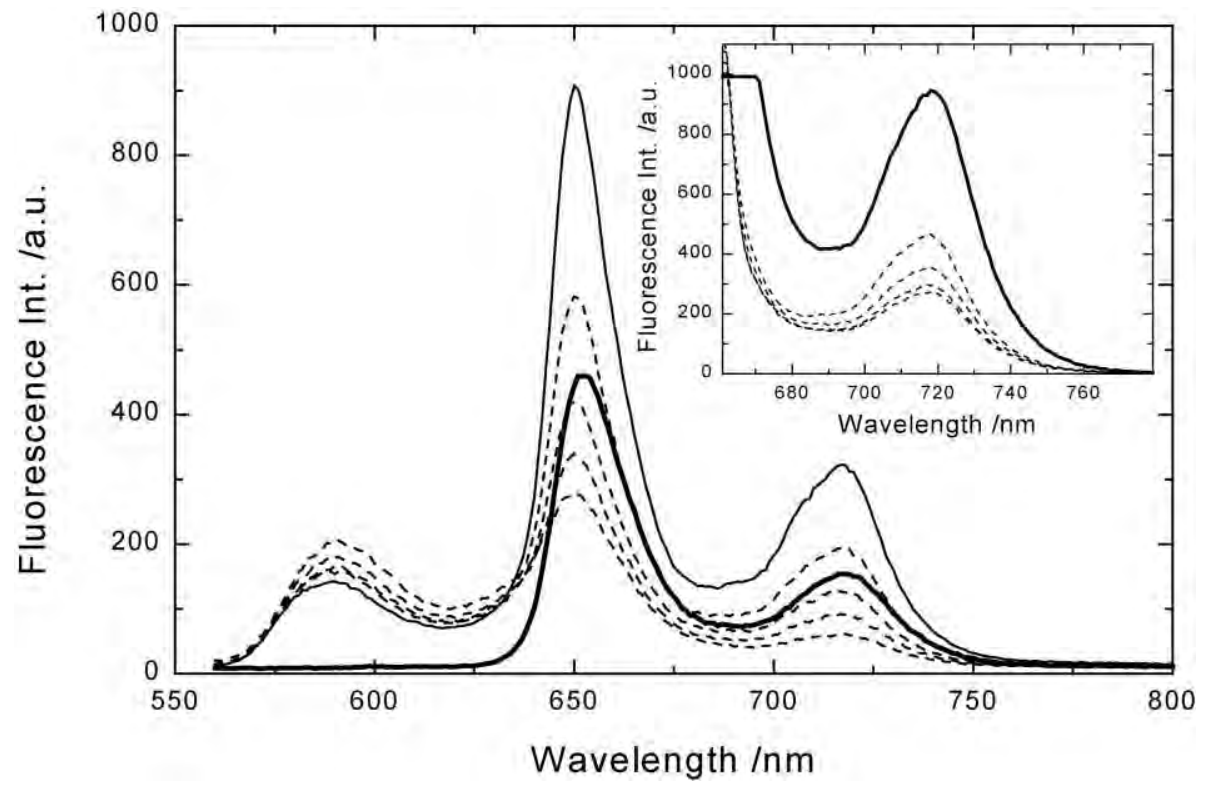

Fig. 5. Corrected fluorescence spectra of the triad $(\mathrm{ZnOEP}){ }_{2} \mathrm{Ph} \otimes \mathrm{H}_{2} \mathrm{P}\left(\mathrm{m}^{\wedge} \mathrm{Pyr}\right)_{2}$-(iso- $\left.\mathrm{PrPh}\right)_{2}\left(x=0.92, c_{\mathrm{D} 0}=2.6 \times 10^{-6} \mathrm{M}, \lambda_{\text {ex }}=546 \mathrm{~nm}\right)$ in toluene (thin solid line) and upon addition of 3,6,9,17 vol.\% of acetone (thin dashed lines). Bold line spectrum represents the pure $\mathrm{H}_{2} \mathrm{P}$ emission in toluene at the same concentration as in triad and at the same excitation conditions. Inset: the same experimental solutions at $\lambda_{\mathrm{ex}}=650 \mathrm{~nm}$ (within longwavelength $Q$-band of the extra-ligand).

vent, acetone $\left(\varepsilon_{\mathrm{st}}=20.7\right.$ [56]) was added to the previously pure toluene $\left(\varepsilon_{\mathrm{st}}=2.38[56]\right)$ solution of the triad. It is clearly seen from Fig. 5 that the subsequent acetone addition manifests itself in a reduction of the extra-ligand fluorescence (bands at 650 and $714 \mathrm{~nm}$ ) at both excitation wavelength of $650 \mathrm{~nm}\left(\mathrm{H}_{2} \mathrm{P}\right.$ absorption $)$ and $546 \mathrm{~nm}$ (dimer absorption). At excitation wavelength of $546 \mathrm{~nm}$ (i. e. into the dimer absorption band presumably) the $\mathrm{H}_{2} \mathrm{P}$ fluorescence intensity in the triad at 0 and $3 \mathrm{vol} \%$ of acetone is larger than that for the pure extra-ligand under the same additions of acetone. This fact indicates EM process from the $\mathrm{S}_{1}$-excited ( $\left.\mathrm{ZnOEP}\right)_{2} \mathrm{Ph}$ to $\mathrm{H}_{2} \mathrm{P}$, as far as the fluorescence of the pure $\mathrm{H}_{2} \mathrm{P}$ solution does not show fluorescence quenching upon acetone addition. The intensity of the dimer fluorescence band at $590 \mathrm{~nm}\left(\lambda_{\mathrm{ex}}=546\right.$ $\mathrm{nm}$ ) increases only slightly indicating that the triads are not destroyed upon acetone addition. It is interesting to note that upon the solvent polarity increase the $\mathrm{H}_{2} \mathrm{P}$ fluorescence quenching in the triad (Fig. 5) goes along with a change of the fluorescence excitation spectrum (Fig. 3) from "triad-like" (i.e. bands corresponding to the absorption bands of $\mathrm{H}_{2} \mathrm{P}$ and the dimer) to "free base-like" (compare with the absorption in Fig. 2). As a result, upon addition of $17 \mathrm{vol} . \%$ of acetone the form of the excitation spectrum of the triad is almost identical to that of the individual extra-ligand $\mathrm{H}_{2} \mathrm{P}$. Nevertheless, the dimer emission in the triad remains strongly quenched upon the solvent polarity increase. It means that in polar media the non-radiative deactivation of the dimer $\mathrm{S}_{1}$-state in the triad does not realise via direct EM process and the formation of CT states of the radical ion pair has to be taken into account.
In order to clarify the real decay times of fluorescing species in the triads TCSPC measurements were performed exciting the dimer moiety at $545 \mathrm{~nm}$ and detecting the emission in the range of 570-740 nm. Three components were used in order to obtain a reasonable fit. Usually experiments were performed with a 1:1 mixture of the dimer and corresponding extra-ligand moieties. Therefore taking into account the values of the complexation constant $K_{\mathrm{C}}$ obtained for every triad (see Table 1) and initial concentrations of reactants we could estimate the content of complexed and uncomplexed components in a solution. Fig. 6 shows this estimation for the triad $(\mathrm{ZnOEP})_{2} \mathrm{Ph} \otimes$ $\mathrm{H}_{2} \mathrm{P}(\mathrm{m} \wedge \mathrm{Pyr})_{2}$-(iso- $\left.\mathrm{PrPh}\right)_{2}$ as well as the amplitude spectra obtained from a global analysis fit using three time

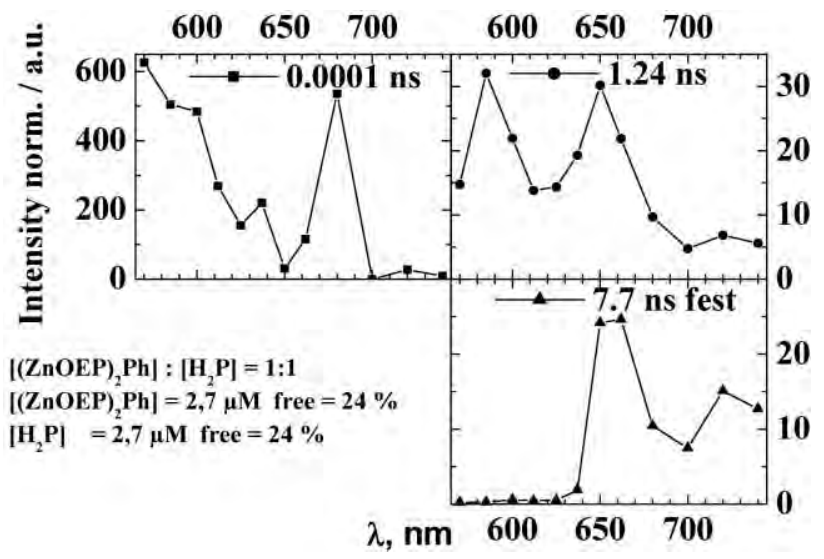

Fig. 6. Decay-associated spectra of the triad $(\mathrm{ZnOEP})_{2} \mathrm{Ph} \otimes \mathrm{H}_{2} \mathrm{P}\left(\mathrm{m}^{\wedge}\right.$ $\mathrm{Pyr})_{2}$-(iso- $\left.\mathrm{PrPh}\right)_{2}$ (toluene, $293 \mathrm{~K}, \lambda_{\mathrm{ex}}=545 \mathrm{~nm}$ ) derived from global analysis of 12 TCSPC time-resolved fluorescence measurements. The global $\chi^{2}$ value was 1.15 . 
constants, which turned out to yield satisfactory results. The shortest component with a decay time of $0.1 \mathrm{ps}$ does not show a real structure and may be attributed to a stray light. This very short component is fitting program dependent (ranging from 0.1 to 27 ps for various triads) when one real long time component is fixed. Correspondingly, it seems to be rather difficult to connect this component with the short-living $(\mathrm{ZnOEP})_{2} \mathrm{Ph}$ subunit in the triad. In this respect, fs pump-probe measurements give exclusively the direct estimations of the decay times of the complexed dimer.

The remaining two components may be easily assigned both due to their decays as well as to the structure of the amplitude spectra to the fluorescing (ZnOEP) ${ }_{2} \mathrm{Ph}$ and extra-ligand species by the following way. The long time constant was hold fixed at $7.7 \mathrm{~ns}$, which is the decay time of the complexed $\mathrm{H}_{2} \mathrm{P}\left(\mathrm{m}^{\wedge} \mathrm{Pyr}\right)_{2}$-(iso- $\left.\mathrm{PrPh}\right)_{2}$. The amplitude spectrum shows the characteristic bands at 650 and $720 \mathrm{~nm}$ of extra-ligand typical fluorescence (Fig. 6). The second component shows the bands at 685 and $640 \mathrm{~nm}$ in its amplitude spectrum with a decay time of $1.24 \mathrm{~ns}$ what is close to the characteristics for the uncomplexed dimer $(\mathrm{ZnOEP})_{2} \mathrm{Ph}$. The additional support for such an explanation was obtained in TCSPC experiments where the extraligand in the triad was excited directly at $650 \mathrm{~nm}$ (i.e. within its absorption longwavelength $Q$-band) and the emission of the complexed extra-ligand was detected at $665 \mathrm{~nm}$ giving the same decay time practically. The results of TCSPC measurements performed for all triads under consideration are presented in Table 2.

Picosecond time resolved fluorescence spectroscopy reveals that the decay time of all complexed extra-ligands is reduced noticeably with respect to that for pure uncomplexed porphyrin and chlorin free bases. It is seen from Table 2 that this decay time shortening becomes stronger upon the solvent polarity rise. In these conditions, the decay time shortening is accompanied by a more pronounced decrease of the extra-ligand fluorescence quantum yield (see Fig. 5). As the extra-ligand moieties show the lowest locally excited $\mathrm{S}_{1}$-state in the triads one would expect them to act as the energy traps which have to show the usual fluorescence decay time typical for the corre- sponding pure extra-ligands. The observation of reduced lifetimes for extra-ligands in the triads can therefore not be explained by EM processes to lower lying locally excited states. Rather the possibilities of ET or other radiationless processes have to be considered.

The analysis of the temperature dependence of the triad $(\mathrm{ZnOEP})_{2} \mathrm{Ph} \otimes \mathrm{H}_{2} \mathrm{P}\left(\mathrm{m}^{\wedge} \mathrm{Pyr}\right)_{2}$-(iso- $\left.\mathrm{PrPh}\right)_{2}$ fluorescence indicates that in a temperature range of $160-278 \mathrm{~K}$, the complexation is complete and any changes in intensity are not due to triad composition or decomposition. At the same time, the fluorescence intensity of complexed $\mathrm{H}_{2} \mathrm{P}$ is decreased upon the temperature lowering. The measured intensity of the $\mathrm{H}_{2} \mathrm{P}$ fluorescence band at $716 \mathrm{~nm}$ was fitted to a Boltzman distribution function (const $+1 /(1+$ $\exp \{\Delta E / k T\}))$ in a temperature range of $160-278 \mathrm{~K}$ and presented in Fig. 7. It follows from these results that the activation energy may be estimated by the value of $\Delta E=$ $0.05 \mathrm{eV}$ in the case of toluene $+7 \mathrm{vol} . \%$ of acetone, while almost no activation energy is found in pure toluene for the same triad.

Thus, "polarity-temperature" experiments presented in Figs. 5, 7 and 8) as well as kinetic data of Table 2 show that the additional deactivation of the extra-ligand locally excited $S_{1}$-state in the triad is due to charge transfer process while the non-radiative deactivation of the dimer locally excited $S_{1}$-state is caused by both EM and ET processes. The above-presented results demonstrate that the competition between EM and ET channels may be driven by properties of surrounding. This competition leads to the complex dynamics of the deactivation of locally excited states in the triads. Quite obviously there is EM from the dimer to the extra-ligand in this case, which leads to the stimulated fluorescence of the extra-ligand (Fig. 3). In fact, upon the excitation of the triad into the dimer absorption bands the population of the extra-ligand locally excited $S_{1}$-state may be realized via direct $E M$ from the dimer $\mathrm{S}_{1}$-state (rate constant $k_{5}$ in Fig. 9) or is due to combined charge transfer processes $\left(k_{6}+k_{8}\right)$. Nevertheless, increasing the polarity of the solvent (addition of acetone) leads to the extra-ligand fluorescence quenching, which may hint to ET process involved even in this case. The excitation spectra in Fig. 3 show that this quenching is

Table 2

Decay times of complexed and uncomplexed components in the triad solutions (toluene, $293 \mathrm{~K}$ ) derived from global analysis of 12 TCSPC time-resolved fluorescence measurements. The triad consists of the $(\mathrm{ZnOEP})_{2} \mathrm{Ph}$ dimer and various extra-ligands

\begin{tabular}{llcc}
\hline Extra-ligand type & $\begin{array}{l}\text { Complexed } \\
\text { extra-ligand }(\tau / \mathrm{ns})\end{array}$ & $\begin{array}{l}\text { Uncomplexed } \\
\text { extra-ligand }\left(\tau_{1} / \mathrm{ns}^{\mathrm{a}}\right)\end{array}$ & $\begin{array}{l}\text { Uncomplexed } \\
\text { dimer }\left(\tau_{2} / \mathrm{ns}\right)\end{array}$ \\
\hline $\mathrm{H}_{2} \mathrm{P}\left(\mathrm{m}^{\wedge} \mathrm{Pyr}\right)_{2}$-(iso-PrPh $)_{2}$ & 7.7 & 9.5 & 1.24 \\
$\mathrm{H}_{2} \mathrm{P}\left(\mathrm{m}^{\wedge} \mathrm{Pyr}\right)_{2}$-(iso-PrPh $)_{2}^{\mathrm{b}}$ & 5.5 & 9.5 & 1.18 \\
$\mathrm{H}_{2} \mathrm{P}\left(\mathrm{p}^{\wedge} \mathrm{Pyr}\right)_{2}$ & 6.6 & 10.0 & 1.27 \\
$\mathrm{H}_{2} \mathrm{P}(\mathrm{m}-\mathrm{Pyr})_{2}$-(iso-PrPh $)_{2}$ & 6.2 & 9.3 & 1.23 \\
$\mathrm{H}_{2} \mathrm{Ch}(\mathrm{m}-\mathrm{Pyr})_{2}$ & 6.6 & 8.3 & 1.24 \\
$\mathrm{H}_{2} \mathrm{THP}(\mathrm{m}-\mathrm{Pyr})_{2}$ & 4.3 & 4.5 & 1.23 \\
\hline
\end{tabular}

\footnotetext{
${ }^{\mathrm{a}}$ The decay times of the uncomplexed extra-ligands have been obtained for solutions with pure extra-ligands in separate experiments, and are presented here for the comparison.

${ }^{\mathrm{b}}$ Toluene +17 vol. $\%$ of acetone.
} 


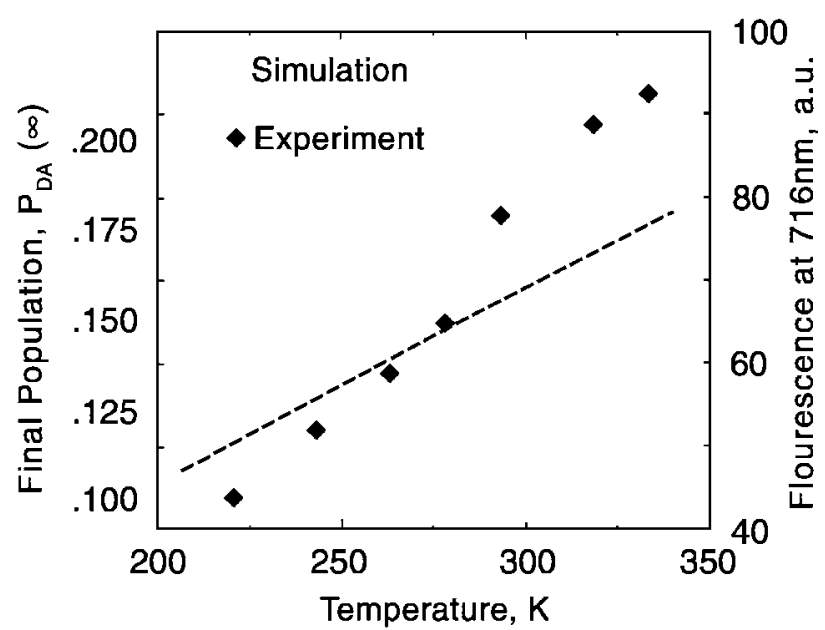

Fig. 7. Temperature dependence of the triad $(\mathrm{ZnOEP})_{2} \mathrm{Ph} \otimes \mathrm{H}_{2} \mathrm{P}\left(\mathrm{m}^{\wedge}\right.$ $\mathrm{Pyr}_{2}$-(iso-PrPh $)_{2}$ fluorescence band at $716 \mathrm{~nm}$ in toluene plus $7 \mathrm{vol} . \%$ of acetone. Experimental points are reasonably fitted by a two level Boltzman distribution as described in the text. The simulation of the equilibrium population $P_{\mathrm{DA}}$ has been carried out using the generalized HakenStrobl-Reineker theory for the description of the photoinduced processes in the triads [57].

not due to faster depopulation of the extra-ligand $S_{1}$-state but caused by a reduction in the amount of energy transferred from the dimer. The excitation band at $646 \mathrm{~nm}$, where only the extra-ligand is excited does not change upon addition of acetone, while the bands at 549 and 585 $\mathrm{nm}$, where the dimer $(\mathrm{ZnOEP})_{2} \mathrm{Ph}$ is excited are reduced. As a result, the excitation spectrum of the triad remains, which is almost identical to the one of the pure extra-ligand.

\subsection{Excited states dynamics (theoretical approach)}

Our preliminary theoretical results [57] have shown that the generalised Haken-Strobl-Reineker formalism [58,59] provides both qualitative and quantitative description of

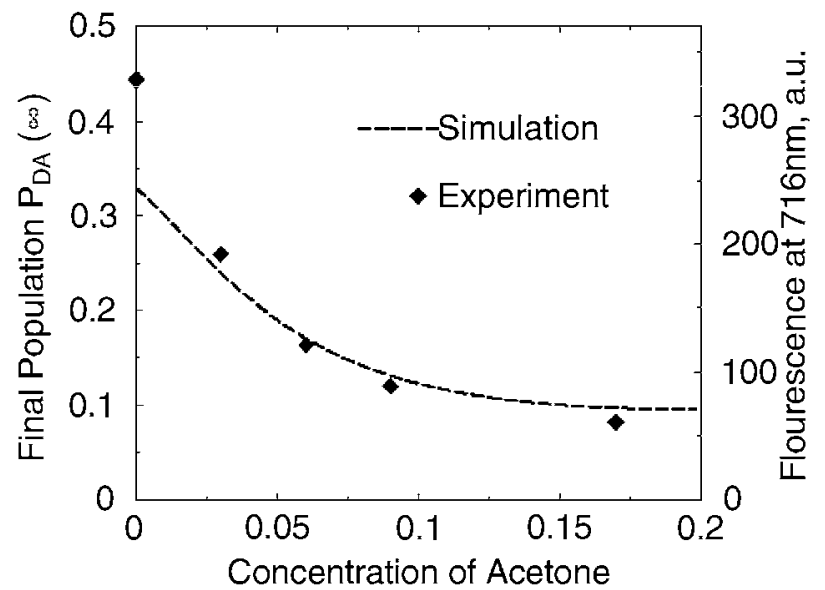

Fig. 8. Solvent polarity dependence of triad $(\mathrm{ZnOEP})_{2} \mathrm{Ph} \otimes \mathrm{H}_{2} \mathrm{P}\left(\mathrm{m}^{\wedge}\right.$ $\mathrm{Pyr})_{2}$-(iso-PrPh $)_{2}$ fluorescence band at $716-720 \mathrm{~nm}$. Experimental points are obtained from the results shown in Fig. 5. The simulation of the equilibrium population $P_{\mathrm{DA}}$ has been carried out using the generalized Haken-Strobl-Reineker theory for the description of the photoinduced processes in the triads [57].

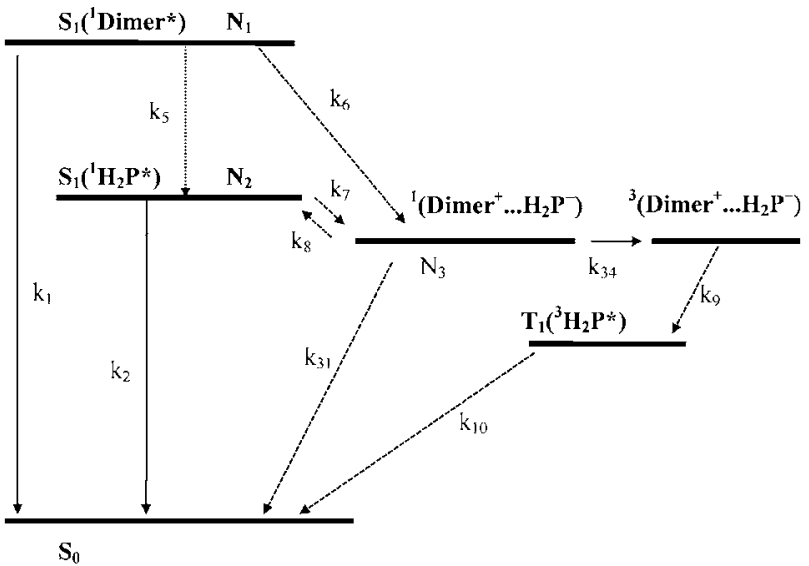

Fig. 9. Schematic energy level diagram for low-lying locally excited singlet states of the dimer $(\mathrm{ZnOEP}){ }_{2} \mathrm{Ph}\left\{\mathrm{S}_{1}\left({ }^{1}\right.\right.$ Dimer $\left.{ }^{*}\right)$, population $\left.\mathrm{N}_{1}\right\}$, $\mathrm{H}_{2} \mathrm{P}\left\{\mathrm{S}_{1}\left({ }^{1} \mathrm{H}_{2} \mathrm{P}^{*}\right)\right.$, population $\left.\mathrm{N}_{2}\right\}$, locally excited triplet state of $\mathrm{H}_{2} \mathrm{P}$ $\left\{\mathrm{T}_{1}\left({ }^{3} \mathrm{H}_{2} \mathrm{P}^{*}\right)\right.$, population $\left.\mathrm{N}_{5}\right\}$ state, charge-transfer singlet state $\left\{{ }^{1}(\mathrm{Di}\right.$ $\left.\operatorname{mer}^{+} \ldots \mathrm{H}_{2} \mathrm{P}^{-}\right)$, population $\left.\mathrm{N}_{3}\right\}$ and charge-transfer triplet state $\left\{{ }^{3}(\mathrm{Di}-\right.$ mer $^{+} \ldots \mathrm{H}_{2} \mathrm{P}^{-}$, population $\mathrm{N}_{4}$ \}. Indicated are rate constants of the following pathways: $k_{1}$, radiative and non-radiative decay of Dimer*; $k_{2}$, radiative and non-radiative decay of $\mathrm{H}_{2} \mathrm{P}$; ( intersystem crossing from the singlet to the triplet state $\mathrm{S}_{1} \sim \sim>\mathrm{T}_{1}$ is not presented); $k_{7}$, hole transfer from the extra-ligand locally excited singlet state to the dimer forming the singlet radical ion pair state; $k_{8}$, charge recombination from the singlet radical ion pair state to the extra-ligand locally excited singlet state (thermally activated for non-fluorinated extra-ligand); $k_{34}$, spin rephasing between the singlet and triplet radical ion pairs; $k_{30}$, charge recombination from the singlet radical ion pair to the ground state; $k_{50}$, non-radiative intersystem crossing to the ground state, $\mathrm{T}_{1} \sim \sim>\mathrm{S}_{0} ; k_{9}$, charge recombination from the triplet radical ion pair to the locally excited triplet state of an extra-ligand.

time-resolved and steady-state properties such as fluorescence quenching of the self-assembled porphyrin triads due to ET and EM processes. The whole theoretical description of relaxation processes in the triads will be presented in forthcoming paper. Here, we present the main ideas of our approach and some details of the comparative analysis of experimental results and theoretical calculations. The theory derived in Refs. $[58,59]$ accounts for the influence of vibrational degrees of freedom by the stochastic change of electronic state energies. From theoretical point of view coherent or incoherent type of electron or exciton transport in the systems under consideration depends on the coupling to the relevant vibrational modes. The generalised Haken-Strobl-Reineker method [58,59] is a stochastic model, which allows treating not only both coherent or incoherent cases but also the whole range in-between. The coherent processes are described by the transition matrix elements between interacting subunits of the triad. The influence of the quantum bath on a single excitation are taken into account by letting fluctuate the energy of the localised excitation and represented by a stochastic potential which is Gaussian, Markovian and $\delta$-correlated in time.

For the triads containing the dimer and the extra-ligand $\mathrm{H}_{2} \mathrm{P}$, the dynamics of the excited states $|1\rangle=\mid$ Dimer * $\left.\mathrm{H}_{2} \mathrm{P}\right\rangle,|2\rangle=\mid$ Dimer $\left.^{+}-\mathrm{H}_{2} \mathrm{P}^{-}\right\rangle$, and $|3\rangle=\mid$ Dimer- $\left.\mathrm{H}_{2} \mathrm{P}^{*}\right\rangle$ 
is described by the equation of motion for the relevant reduced density matrix [58,59] with neglecting of the vibrational substructure of the electronic states [60].

$$
\begin{aligned}
\frac{\partial}{\partial t} \sigma_{\kappa \lambda}= & -\frac{i}{\eta}\left(\left[H_{\mathrm{S}}, \sigma\right]\right)_{\kappa \lambda}+2 \delta_{\kappa \lambda}\left\{\Gamma_{\mu \kappa}\left[n\left(\omega_{\mu \kappa}\right)+1\right]\right. \\
& \left.+\Gamma_{\kappa \mu} n\left(\omega_{\kappa \mu}\right)\right\} \sigma_{\mu \mu}-\Sigma_{\mu}\left\{\Gamma_{\mu \kappa}\left[n\left(\omega_{\mu \kappa}\right)+1\right]\right. \\
& +\Gamma_{\kappa \mu} n\left(\omega_{\kappa \mu}\right)+\Gamma_{\mu \lambda}\left[n\left(\omega_{\mu \lambda}\right)+1\right] \\
& \left.+\Gamma_{\lambda \mu} n\left(\omega_{\lambda \mu}\right)\right\} \sigma_{\kappa \lambda}+\left\{\Gamma_{\lambda \kappa}\left[2 n\left(\omega_{\lambda \kappa}\right)+1\right]\right. \\
& \left.+\Gamma_{\kappa \lambda}\left[2 n\left(\omega_{\kappa \lambda}\right)+1\right]\right\} \sigma_{\lambda \kappa} .
\end{aligned}
$$

Here, the triad Hamiltonian $H_{\mathrm{S}}$ includes the energies $E_{\lambda}$ of the corresponding states and couplings between them, $n(\omega)=\left[\exp \left(\eta \omega / k_{\mathrm{B}} T\right)-1\right]^{-1}$ denotes Bose-Einstein distribution, $\Gamma_{\kappa \lambda}$ the damping constant, and $\kappa, \lambda$, $\mu=1,2,3$. For the sake of convenience of the numerical calculations, we replace $\Gamma_{\mu \nu}$ and the population of the corresponding bath mode $n\left(\omega_{\mu \nu}\right)$ with the dissipative transitions $d_{\mu \nu}=\Gamma_{\mu \nu}\left|n\left(\omega_{\mu \nu}\right)\right|$ and the corresponding dephasings $\gamma_{\mu \nu}=\Sigma_{k}\left(d_{\mu \nu}+d_{\mu \nu}\right) / 2$. In such model, one describes the porphyrin triad with the relevant potential energy surfaces in the space of a single reaction coordinate, which reflect the extent of the solvent polarisation induced by the field of the triad.

In order to describe the relaxation processes in the triads physically reasonable values of the model parameters, such as the energies of locally excited and CT states as well as coherent and dissipative couplings have to be appropriately chosen. The energies $E_{1}=2.1 \mathrm{eV}$ (locally excited $\mathrm{S}_{1}$-state of the dimer), $E_{2}=1.90 \mathrm{eV}$ (charge transfer state, CT, in toluene at $293 \mathrm{~K})$ and $E_{3}=1.91$ $\mathrm{eV}\left(\mathrm{S}_{1}\right.$-state of the extra-ligand) for the triads containing ( $\mathrm{ZnOEP})_{2} \mathrm{Ph}$ and $\mathrm{H}_{2} \mathrm{P}\left(\mathrm{m}^{\wedge} \mathrm{Pyr}\right)_{2}$-(iso- $\left.\mathrm{PrPh}\right)_{2}, \mathrm{H}_{2} \mathrm{P}(\mathrm{m}-\mathrm{Pyr})_{2}$ (iso- $\mathrm{PrPh})_{2}$ and $\mathrm{H}_{2} \mathrm{P}\left(\mathrm{p}^{\wedge} \mathrm{Pyr}\right)_{2}$ are taken from our previous paper [17]. The energy of CT state $|2\rangle$ depending on the solvent polarity has been calculated using Weller's formula [61]

$$
\begin{aligned}
E_{2}(\varepsilon)= & E_{2}\left(\varepsilon_{t}\right) \\
& +\left(\frac{1}{\varepsilon}-\frac{1}{\varepsilon_{t}}\right) \frac{e^{2}}{4 \pi \varepsilon_{0}}\left(\frac{1}{2 r_{\mathrm{D}}}+\frac{1}{2 r_{\mathrm{A}}}-\frac{1}{r_{\mathrm{DA}}}\right) .
\end{aligned}
$$

In the case of the solvent mixture consisting of toluene and a small amount of acetone, the effective dielectric constant of the mixture may be found assuming that the Onsager function of the mixture is a sum of the Onsager functions of the individual components [62]. Values of the reorganisation energy have been calculated like in our previous papers $[17,48]$ using known $D$ and $A$ radii $r_{\mathrm{D}}$, $r_{\mathrm{A}}, D-A$ distances $r_{\mathrm{DA}}$ in the triads and solvent properties (see below and Fig. 1)

$\lambda_{\text {solv }}=\frac{e^{2}}{4 \pi \varepsilon_{0}}\left[\frac{1}{2 r_{\mathrm{D}}}+\frac{1}{2 r_{\mathrm{A}}}-\frac{1}{r_{\mathrm{DA}}}\right]\left[\frac{1}{\varepsilon_{o p}}-\frac{1}{\varepsilon}\right]$.

The reasonable values of the couplings and relaxation constants estimated from known experimental data for porphyrins and related systems are presented in Table 3 .

As it follows from the experimental results, the competition between charge transfer and energy migration cause a rather complex dynamics in the triads at $293 \mathrm{~K}$. Mathematically, it is easy to calculate the system state at the infinite time $t=\infty$. As far as in the triad $(\mathrm{ZnOEP})_{2} \mathrm{Ph} \otimes$ $\mathrm{H}_{2} \mathrm{P}\left(\mathrm{m}^{\wedge} \mathrm{Pyr}\right)_{2}$-(iso- $\left.\mathrm{PrPh}\right)_{2}$ ET time $\left(t_{\mathrm{ET}} \approx 1.7 \mathrm{ps}\right)$ is much shorter than fluorescence decay time of extra-ligand $\left(\tau_{\mathrm{S}}=\right.$ $7.7 \mathrm{~ns}$ ), we may approximate $t=\infty$ with some time moment $t$ when ET has finished and the fluorescence has not occurred yet. On this time $t_{\mathrm{ET}}<t<\tau_{\mathrm{S}}$, the system reaches the quasi-thermal equilibrium between the excited state $|3\rangle$ and close lying CT state $|2\rangle$.

For each parameter set, the relevant reduced density matrix $\sigma_{\kappa \lambda}(t)$ has been numerically calculated. At $t=\infty$ the diagonal elements of density matrix arrive to the quasi-equilibrium values. Really, these values correspond to the stationary fluorescence intensity of the triad subunits. Here we are interested in the equilibrium population of the state $|3\rangle$ calculated numerically with the generalised Haken-Strobl-Reineker method. This population corresponds to the presence of the fluorescence into the ground state. We denote the population of this state with $P_{\mathrm{DA}^{*}}=\rho_{33}$. Taking into account parameters collected in Table 2 , it has been found that $P_{\mathrm{DA}^{*}}(\infty)$ decreases in two cases: (i) lowering of the CT state energy $E_{2}$ (induced by increase of the solvent polarity) and (ii) lowering of the temperature. As one can see from Figs. 7 and 8, calculated dependencies of the extra-ligand $\mathrm{H}_{2} \mathrm{P}$ population in the $\mathrm{S}_{1}$-state $P_{\mathrm{DA}^{*}}(\infty)$ on temperature and solvent polarity are in a reasonable agreement with the observed fluorescence quenching.

Table 3

Coherent and dissipative couplings between electronic states for the triad $(\mathrm{ZnOEP})_{2} \mathrm{Ph} \otimes \mathrm{H}_{2} \mathrm{P}\left(\mathrm{m}^{\wedge} \mathrm{Pyr}\right)_{2}$-(iso- $\left.\mathrm{PrPh}\right)_{2}$

\begin{tabular}{lcll}
\hline Coupling & Value $(\mathrm{meV})$ & Physical process & Comment \\
\hline$v_{12}$ & 60 & Electron transfer $D^{*} A \rightarrow D^{+} A^{-}$ & Induced by the wave function overlap \\
$\nu_{32}$ & 3 & Hole transfer $D^{*} A \rightarrow D^{+} A^{-}$ & Weakened by the screening field of the electron from the LUMO of the acceptor \\
$v_{13}$ & 12 & Energy transfer $D^{*} A \rightarrow D A^{*}$ & Induced by the dipole-dipole interaction $v_{13} \sim \mu_{\mathrm{D}} \cdot \mu_{\mathrm{A}} / r_{\mathrm{DA}}^{3}$ \\
$\Gamma_{12}$ & 0.41 & Loss of coherence for $D^{*} A \rightarrow D^{+} A^{-}$ & Interaction of the transition dipole moment with environmental dipoles \\
$\Gamma_{32}$ & 2.50 & Loss of coherence for $D^{*} A \rightarrow D^{+} A^{-}$ & Induced by the interaction with the environment \\
$\Gamma_{13}$ & 0.37 & Loss of coherence for $D^{*} A \rightarrow D A^{*}$ & Estimated by taking into account other dissipation $\gamma_{i j}=\sum_{\kappa}\left(d_{i k}+d_{k j}\right)$
\end{tabular}


Thus, the quenching of the extra-ligand fluorescence in the triad originates from the hole transfer $|3\rangle \rightarrow|2\rangle$ from the extra-ligand to the $\mathrm{Zn}$-porphyrin dimer being weakened by thermal exchange of the close lying charge transfer and extra-ligand locally excited $\mathrm{S}_{1}$-states. The variation of the solvent polarity (acetone addition) and temperature changes $\mathrm{H}_{2} \mathrm{P}$ fluorescence intensity (the population $\rho_{33}$ ) as well as a character of the excited states dynamics.

Our simulations display that the time dependence of the population $\rho_{33}$ as well as its temperature dependence at low acetone concentration qualitatively differs from the behaviour at high acetone concentration. It means that under various experimental conditions, different reaction mechanisms may be realized. As far as the detailed analysis of these results will be presented in forthcoming paper, we may conclude the following. At low acetone concentrations ( $0-7 \mathrm{vol} . \%)$ the quasi-thermal equilibrium population $P_{\mathrm{DA}^{*}}(\infty)$ is reached in one-step (due to EM process presumably) and a reaction rate constant can be found with an one-exponential fit. In the case of high acetone concentration (10-20 vol.\%), the energy detuning between states $|2\rangle$ and $|3\rangle$ becomes larger. Correspondingly, in addition to EM process, the hole transfer $|3\rangle \rightarrow|2\rangle$ takes place, thus the equilibrium population $P_{\mathrm{DA}^{*}}(\infty)$ is reached in two steps. The reaction occurs with the help of a sequential transfer, which is described by two rates (increase and decrease) and the one-exponential fit for a reaction rate constant can not be used in this case. At last, it is interesting to note that at high acetone concentrations (10-20 vol.\%) the energy gap $\Delta E=E_{3}-E_{2}$ becomes larger, and two regimes $k_{\mathrm{B}} T>\Delta E$ and $k_{\mathrm{B}} T<\Delta E$ may be realized upon temperature changing. The first case corresponds to the one-step reaction, while the second case reflects the two-step reaction. Correspondingly, for high acetone admixture in toluene the increase of temperature induces the crossover from the second (coherent) to the first (incoherent) type of behaviour.

\subsection{Comparative analysis of various triads}

It is interesting to compare the extra-ligand fluorescence quenching (Table 2) in the triads containing the same dimer ( $\mathrm{ZnOEP})_{2} \mathrm{Ph}$ but having different geometry $\left[\left(\mathrm{H}_{2} \mathrm{P}\left(\mathrm{m}^{\wedge} \mathrm{Pyr}\right)_{2} \text {-(iso- } \mathrm{PrPh}\right)_{2}, \mathrm{H}_{2} \mathrm{P}(\mathrm{m}-\mathrm{Pyr})_{2} \text {-(iso- } \mathrm{PrPh}\right)_{2}$ and $\left.\left.\mathrm{H}_{2} \mathrm{P}\left(\mathrm{p}^{\wedge} \mathrm{Pyr}\right)_{2}\right)\right]$ or extra-ligands of various nature $\left[\left(\mathrm{H}_{2}\right.\right.$ $\mathrm{P}(\mathrm{m}-\mathrm{Pyr})_{2}$-(iso- $\left.\mathrm{PrPh}\right)_{2}, \mathrm{H}_{2} \mathrm{Chl}(\mathrm{m}-\mathrm{Pyr})_{2}$ and $\mathrm{H}_{2} \mathrm{THP}(\mathrm{m}-$ $\left.\left.\mathrm{Pyr})_{2}\right)\right]$.

First of all, we will have a look at the redox-potentials of the porphyrins and chlorins under study, which determine the energetic feasibility of ET process. The free enthalpies of the charge separated state may be written as $G=E_{\mathrm{D}}^{\mathrm{ox}}-E_{\mathrm{A}}^{\mathrm{red}}+\Delta G(\varepsilon)[63]$, where $E_{\mathrm{D}}^{\mathrm{ox}}$ is the $D$ oxidation potential, $E_{\mathrm{A}}^{\text {red }}$ the $A$ reduction potential and $\Delta G(\varepsilon)$ accounts for the differences in dielectric constants between the solvent in which the redox potentials were measured and the solvent in which $G$ shall be calculated as well as for Coulombic interaction of the cation and anion. In polar solvents $E_{\mathrm{D}}^{\mathrm{ox}}=+0.63 \mathrm{eV}$ (butyronitrile vs. SCE) for ZnOEP [64]. Reduction potentials for extra-ligands have been extracted from literature data [64,65] taking into account that pyridyl substituents increase the reduction potential of free base porphyrins and chlorins [66]: $E_{\mathrm{A}}^{\text {red }}$ $\left(\mathrm{H}_{2} \mathrm{P}\right)=-1.01 \mathrm{eV}$ (dimethylformamide, DMF vs. SCE), $E_{\mathrm{A}}^{\text {red }}\left(\mathrm{H}_{2} \mathrm{Chl}\right)=-1.05 \mathrm{eV}(\mathrm{DMF}$ vs. SCE $), E_{\mathrm{A}}^{\text {red }}\left(\mathrm{H}_{2} \mathrm{TPP}\right)$ $=-1.03 \mathrm{eV}$ (DMF vs. SCE). The estimations of $\Delta G(\varepsilon)$ for the triads have been done using well-known expression $[61,63]$

$$
\begin{aligned}
\Delta G(\varepsilon)= & \frac{e^{2}}{4 \pi \varepsilon_{0}}\left[\left(\frac{1}{2 r_{D}}+\frac{1}{2 r_{A}}-\frac{1}{r_{D A}}\right) \frac{1}{\varepsilon}\right. \\
& \left.-\left(\frac{1}{2 r_{D}} \frac{1}{\varepsilon_{D}^{\prime}}+\frac{1}{2 r_{A}} \frac{1}{\varepsilon_{A}^{\prime}}\right)\right],
\end{aligned}
$$

donor and acceptor radii $r_{\mathrm{D}}=r_{\mathrm{A}}=5.5 \AA$, intercenter distances $r_{\mathrm{DA}}$ from the optimised structures (Fig. 1), and dielectric constants of the solutions $\varepsilon$ (butyronitrile) $=24.8$, $\varepsilon($ benzonitrile $)=25.2, \quad \varepsilon(\mathrm{DMF})=36.7, \quad \varepsilon$ (toluene $)=$ 2.38. As a result, Table 4 collects the experimental values of the energies of locally excited $S_{1}$-states for all extraligands and estimated values of the energy of CT states for the corresponding triads.

In fact, according to results presented in Table 2 despite of different structures of three triads containing $\left(\mathrm{H}_{2} \mathrm{P}\left(\mathrm{m}^{\wedge}\right.\right.$ $\mathrm{Pyr})_{2}$-(iso- $\left.\mathrm{PrPh}\right)_{2}, \mathrm{H}_{2} \mathrm{P}(\mathrm{m}-\mathrm{Pyr})_{2}$-(iso- $\left.\mathrm{PrPh}\right)_{2}$ and $\mathrm{H}_{2} \mathrm{P}$ ( $\mathrm{p}^{\wedge}$ Pyr) ${ }_{2}$ ) (Fig. 1), the extra-ligand $\tau_{\mathrm{S}}$ shortening has the same order of magnitude for all these systems in toluene at 293 K. From data of Table 4, it follows that CT states for the electron transfer $(\mathrm{ZnOEP})_{2} \mathrm{Ph} \rightarrow \mathrm{H}_{2} \mathrm{P}$ are very close or approximately isoenergetic with locally excited $\mathrm{S}_{1}$-states of these extra-ligands. Therefore, it may be concluded that deviations of intercenter distances $r_{\mathrm{DA}}$ for these triads with the different orientation of extra-ligands with respect to the dimer plane do not lead to principal changes of ET rate constants. This fact may be explained by a close proximity of extra-ligand macrocycles to $\pi$-conjugated electronic system of the dimer. In a result, electronic coupling determined by the overlap of $D$ and $A$ periferic orbitals is strong enough and does not change essentially upon the geometrical reorganisation of the same electron acceptor in the triad. The second reason of the same quenching effect observed for triads with $\mathrm{H}_{2} \mathrm{P}\left(\mathrm{m}^{\wedge} \mathrm{Pyr}\right)_{2}$ -

Table 4

Energetic parameters of the triads containing $(\mathrm{ZnOEP})_{2} \mathrm{Ph}$ and various extra-ligands (toluene, $293 \mathrm{~K}$ )

\begin{tabular}{lll}
\hline Extra-ligand & $E\left(\mathrm{~S}_{1}\right) / \mathrm{eV}$ & $E(\mathrm{CT}) / \mathrm{eV}$ \\
\hline$\left(\mathrm{H}_{2} \mathrm{P}\left(\mathrm{m}^{\wedge} \mathrm{Pyr}\right)_{2} \text {-(iso-PrPh }\right)_{2}$ & 1.91 & 1.90 \\
$\mathrm{H}_{2} \mathrm{P}\left(\mathrm{p}^{\wedge} \mathrm{Pyr}\right)_{2}$ & 1.91 & 1.89 \\
$\mathrm{H}_{2} \mathrm{P}(\mathrm{m}-\mathrm{Pyr})_{2}$-(iso-PrPh $)_{2}$ & 1.91 & 1.93 \\
$\mathrm{H}_{2} \mathrm{Chl}(\mathrm{m}-\mathrm{Pyr})_{2}$ & 1.89 & 1.97 \\
$\mathrm{H}_{2} \mathrm{THP}(\mathrm{m}-\mathrm{Pyr})_{2}$ & 1.66 & 1.95
\end{tabular}


(iso- $\mathrm{PrPh})_{2}$ and $\mathrm{H}_{2} \mathrm{P}\left(\mathrm{p}^{\wedge} \mathrm{Pyr}\right)_{2}$ may be connected with a possible role of pyridyl rings as spacers between interacting $D$ and $A$ subunits. According to arguments presented in Ref. [67] for both the HOMO and the LUMO, the orbital density is greater at the ortho- and para-positions than it is at the meta-position of the phenyl spacer. Therefore, it seems reasonable to suggest that this tendency is operative in the triads. Correspondingly, the electronic coupling of the dimer and the extra-ligand, as mediated by the superexchange interaction [67], will also be strong at the para-case $\left(\mathrm{H}_{2} \mathrm{P}\left(\mathrm{p}^{\wedge} \mathrm{Pyr}\right)_{2}\right)$ in spite of greater intercenter distance $r_{\mathrm{DA}}$ with respect to the meta-case $\left(\mathrm{H}_{2} \mathrm{P}\left(\mathrm{m}^{\wedge}\right.\right.$ $\mathrm{Pyr}_{2}$-(iso- $\left.\mathrm{PrPh}\right)_{2}$ ).

The comparative analysis of data collected for the triad with $\mathrm{H}_{2} \mathrm{Chl}(\mathrm{m}-\mathrm{Pyr})_{2}$ in Tables 2 and 4 shows that the experimentally observed additional deactivation of $\mathrm{S}_{1}$-state of this extra-ligand and the energetic reasons of a such tendency are practically the same like in previous case. Correspondingly, the non-radiative deactivation of locally excited $\mathrm{S}_{1}$-states for $\mathrm{H}_{2} \mathrm{P}$ and $\mathrm{H}_{2} \mathrm{Chl}$ extra-ligands may realise via the thermal activation of the radical ion pair states followed by the charge recombination from these states to the ground state or to the low-lying locally excited $\mathrm{T}_{1}$-state of the electron acceptor (extra-ligand). In addition, according with [68] the $\tau_{\mathrm{S}}$ shortening for these extra-ligands in the triads may be enhanced by mixing of close-lying CT state with a locally excited $S_{1}$-state thus leading to the rise of the non-radiative transitions between $\mathrm{S}_{1}$ - and $\mathrm{S}_{0}$-states in the acceptor subunit. At last, for the triad with $\mathrm{H}_{2} \mathrm{THP}(\mathrm{m}-\mathrm{Pyr})_{2}$ the energy of the locally excited $\mathrm{S}_{1}$-state is smaller by $0.29 \mathrm{eV}$ in comparison with the energy of CT state. Thus, both quenching mechanisms being discussed are switched off practically, and $\mathrm{H}_{2}$ THP $(\mathrm{m}-\mathrm{Pyr})_{2}$ fluorescence quenching is not detected in this case.

Finally, it should be noted that for the triads with $\mathrm{H}_{2} \mathrm{P}$ the effective formation of the extra-ligand $\mathrm{T}_{1}$-state is observed. The decay time of the extra-ligand in the triad $\left(\tau_{\mathrm{T}}=1.3 \mathrm{~ms}\right.$ in degassed toluene at $\left.293 \mathrm{~K}\right)$ is practically the same with respect to that for pure $\mathrm{H}_{2} \mathrm{P}$ at the same conditions. In this triad, the locally excited $\mathrm{T}_{1}$-state of $\mathrm{H}_{2} \mathrm{P}$ $\left(E_{\mathrm{T}}=1.44 \mathrm{eV}\right.$ [46]) lies essentially lower that $\mathrm{CT}$ state (Fig. 9). Therefore in the triad the upper lying CT state does not influence on the deactivation of the locally excited $\mathrm{T}_{1}$-state of the extra-ligand. From the other hand, rate constants of ET process with participation of the dimer and extra-ligand $\mathrm{S}_{1}$-states $\left(k_{6}, k_{7}>10^{10} \mathrm{~s}^{-1}\right)$ in the triad are essentially higher than the rate constant of the intersystem crossing $\mathrm{S}_{1} \sim \sim>\mathrm{T}_{1}$ in porphyrin free bases $\left(r=5 \times 10^{7}\right.$ $\mathrm{s}^{-1}$ [46]). It means that the direct population of the extraligand locally excited $T_{1}$-state is probably low in the triad. In this case the population of the extra-ligand locally excited $\mathrm{T}_{1}$-state realised from the upper lying triplet radical ion pair state ${ }^{3}\left(\right.$ Dimer $\left.^{+} \ldots \mathrm{H}_{2} \mathrm{P}^{-}\right)$which in its turn may be populated via the spin rephasing between the singlet and triplet radical ion pairs (rate constant $k_{34}$, Fig. 9).

\section{Conclusions}

With a view to better understanding the possible mechanisms of the initial photoprocesses in photosynthetic systems in vivo, the excited state dynamics have been comparatively studied for a series of conformationally restricted self-assembled triads of tetrapyrrole compounds in liquid solutions and rigid polymeric films. The steady-state and time-resolved fluorescence data evidently show that in self-assembled triads containing chemical Zn-porphyrin dimer and various tetrapyrrole extra-ligands the competition of charge transfer and energy transfer between the dimer and extra-ligand cause rather complex dynamics depending on a temperature and polarity of the solvent. Calculated dependencies of the extra-ligand $\left(\mathrm{H}_{2} \mathrm{P}\right)$ population in the $\mathrm{S}_{1}$-state reflecting the intensity of its fluorescence on temperature and solvent polarity are in a reasonable accordance with experimental data. On the base of the performed experimental and theoretical investigations one concludes that the charge transfer processes induce the quenching of the singlet locally excited states of the triad. Both EM and ET from Zn-porphyrin dimer to the extraligand cause the dimer $S_{1}$-state quenching. The quenching of the extra-ligand $S_{1}$-state originates from the hole transfer to the Zn-porphyrin dimer from the extra-ligand being weakened by thermal exchange of the close lying charge transfer and extra-ligand locally excited $\mathrm{S}_{1}$-states. The results of this study provide a good background for the investigation of the relaxation dynamics in porphyrin triads and pentads with additional electron acceptors of nonporphyrin nature, modelling the primary charge separation in vivo. This study is in a progress in our group.

\section{Acknowledgements}

Financial support from DAAD Grant (Germany, Referat 325 ) for one of the co-workers (Z.E.I) is gratefully acknowledged.

\section{References}

[1] V. Sundstrom, T. Pullerits, R. van Grondele, J. Phys. Chem. 103 (1999) 2327-2346.

[2] X. Hu, A. Damjanovic, T. Ritz, K. Shulten, Proc. Natl. Acad. Sci. U. S. A. 95 (1998) 5935-5941.

[3] K.E. McAuley, P.K. Fyfe, R.J. Cogdell, N.W. Isaacs, M.R. Jones, FEBS Lett. (2000) 285-290.

[4] K.-H. Rhee, E.P. Morris, J. Barber, W. Kuhlbrandt, Nature 396 (1998) 283-286.

[5] C. Tietz, O. Chehlov, A. Drabenstedt, J. Shuster, J. Wrachtrup, J. Phys. Chem. 103 (1999) 6328-6333.

[6] L. Laporte, C. Kirmaier, C. Schenck, D. Holten, Chem. Phys. 197 (1995) 225-273.

[7] G.R. Fleming, G.L. Martin, J. Breton, Nature (London) 333 (1988) 190-192.

[8] V. Balzani, F. Scandola, Supramolecular Photochemistry, Ellis Horwoord, New York, 1991.

[9] H.J. Schneider, H. Durr (Eds.), Frontiers in Supramolecular Organic Chemistry and Photochemistry, Verlag Chemie, Weinheim, 1991. 
[10] M.C. Petty, M.R. Bryce, D. Bloor (Eds.), An Introduction to Molecular Electronics, Edward Arnold A Division of Holder Headline PLC, London, 1995.

[11] J. Fan, J.A. Whiteford, B. Olenyuk, M.D. Levin, P.J. Stang, E.B. Fleischer, J. Am. Chem. Soc. 121 (1999) 2741-2752.

[12] R.T. Hayes, M.R. Wasielewski, D. Gosztola, J. Am. Chem. Soc. 122 (2000) 5563-5567.

[13] J.P. Sumida, P.A. Liddell, S. Lin, A.N. Macpherson, G.R. Seely, A. Moore, T.A. Moore, D. Gust, J. Phys. Chem. A 102 (1998) 55125519.

[14] R.W. Wagner, J. Seth, S.I. Yang, D. Kim, D.F. Bocian, D. Holten, J.S. Lindsey, J. Org. Chem. 63 (1998) 5042-5049.

[15] T. Yamazaki, I. Yamazaki, A. Osuka, J. Phys. Chem. B 102 (1998) $7858-7865$

[16] E.I. Zenkevich, A.M. Shulga, S.M. Bachilo, U. Rempel, J. von Richthofen, C. von Borczyskowski, J. Lumin. 76/77 (1998) 354358.

[17] S. Bachilo, A. Willert, U. Rempel, A.M. Shulga, E.I. Zenkevich, C. von Borczyskowski, J. Photochem. Photobiol., A: Chem. 126 (1999) 99-109.

[18] M.R. Wasielewski, D.J. Johnson, W.A. Swec, K.M. Kersey, D.W Minsek, J. Am. Chem. Soc. 110 (1988) 7219-7221.

[19] D.J. Johnson, M.P. Niemczyk, D.W. Minsek, G.P. Wiererrechy, W.A. Svec, G.L. Gaines III, M.R. Wasielewski, J. Am. Chem. Soc. 115 (1993) 5692-5699.

[20] J.L. Sessler, M.R. Johnson, T.-Y. Lin, Tetrahedron 165 (1989) 392-396.

[21] A. Osuka, K. Maruyama, I. Yamazaki, N. Chem. Phys. Lett. 45 (1990) 4767-4784.

[22] M.R. Wasielewski, G.L. Gaines III, M.P. O'Neil, W.A. Svec, M.P. Niemczyk, L. Prodi, D. Gosztola, in: N. Mataga, T. Okada, H. Masuhara (Eds.), Dynamics and Mechanisms of Photoinduced Transfer and Related Phenomena. Elsevier, New York, 1992, pp. 87-103.

[23] D. Gust, T.A. Moore, A.L. Moore, C. Devados, P.A. Liddell, R. Hermant, R.A. Nieman, L.G. Demanche, J.M. DeGraziano, I. Gouni, J. Am. Chem. Soc. 114 (1992) 3590-3603.

[24] U. Rempel, B. von Maltzan, C. von Borczyskowski, J. Lumin. 53 (1992) 175

[25] D. Gust, T.A. Moore, A.L. Moore, A.N. Macpherson, A. Lopez, J.M. DeGraziano, I. Gouni, E. Bittesmann, G.R. Seely, F. Gao, R.A. Nieman, X.C. Ma, L. Demanche, D.K. Luttrull, S.-J. Lee, P.K. Kerrigan, J. Am. Chem. Soc. 115 (1993) 11141-11152.

[26] E.I. Zenkevich, A.M. Shulga, A.V. Chernook, E.I. Sagun, G.P. Gurinovich, Proc. Indian Acad. Sci. Chem. Sci. 107 (1995) 795-802.

[27] V.V. Borovkov, R.P. Evstigneeva, A.A. Gribkov, Khim. Geterotskl. Soedin. (3) (1995) 343.

[28] U. Rempel, B. von Maltzan, C. von Borczyskowski, Chem. Phys. Lett. 245 (1995) 253-261.

[29] A. Harriman, J.-P. Sauvage, Chem. Soc. Rev. 25 (1996) 41-48.

[30] A. Starukhin, E. Zenkevich, A. Shulga, A. Chernook, J. Lumin. 68 (1996) 313-323.

[31] A. Osuka, S. Marumo, N. Mataga, S. Taniguchi, T. Okada, I. Yamazaki, Y. Nishimura, T. Ohno, K. Nozaki, J. Am. Chem. Soc. 118 (1996) $155-168$.

[32] E.I. Zenkevich, V.N. Knyukshto, A.M. Shulga, V.A. Kuzmitzkii, V.I. Gael, E.G. Levinson, A.F. Mironov, J. Lumin. 75 (1997) 229-244.

[33] D. Kuciauskas, P.A. Liddell, S.-C. Hung, S. Lin, S. Stone, G.R. Seely, A.L. Moore, T.A. Moore, D. Gust, J. Phys. Chem. B 101 (1997) 429-440.

[34] W.B. Davis, M.R. Wasielewski, M.A. Ratner, J. Phys. Chem. 101 (1997) 6158-6164.

[35] Th. Forster, Delocalized excitation and excitation transfer, Modern Quantum Chemistry, vol. 3, Acad. Press, New York, 1965, pp. 93-118.
[36] D.L. Dexter, J. Chem. Phys. 21 (1953) 836-850

[37] S.I. Yang, R.K. Lammi, J. Seth, J.A. Riggs, T. Arai, D. Kim, D.F. Bocian, D. Holten, J.S. Lindsey, J. Phys. Chem. B 102 (1998) 9426-9436.

[38] J.C. Chang, J. Chem. Phys. 67 (1977) 3901-3909.

[39] K.D. Truong, A.D. Bondrauk, T.H. Tran-Thi, P. Grenier, D. Houde, S. Palacin, Thin Solid Films 244 (1994) 981-984.

[40] J.L. Sessler, B. Wang, A. Harriman, J. Am. Chem. Soc. 117 (1995) 704-711.

[41] H. Tamiaka, M. Amakawa, Y. Shimono, R. Tanikaga, A.R. Holzwarth, K. Schaffner, Photochem. Photobiol. 63 (1996) 92-99.

[42] J.A.I. Oksanen, E.I. Zenkevich, V.N. Knyukshto, S. Pakalnis, P.H. Hynninen, J.E.I. Korrpi-Tommola, Biochim. Biophys. Acta-Bioenergetics 1321 (1997) 165-178.

[43] J.-M. Lehn, From molecular recognition towards information and signal processing at the supramolecular level, in: H.-J. Schneider, H. Durr (Eds.), Frontiers in Supramolecular Organic Chemistry and Photochemistry, VCH Verlagsgesellschaft, Weiheim, 1991, pp. 1-28.

[44] A.V. Chernook, A.M. Shulga, E.I. Zenkevich, U. Rempel, C. von Borczyskowski, J. Phys. Chem. 100 (1996) 1918-1926.

[45] A.V. Chernook, U. Rempel, C. von Borczyskowski, E.I. Zenkevich, A.M. Shulga, Chem. Phys. Lett. 254 (1996) 229-241.

[46] E.I. Zenkevich, A.M. Shulga, S.M. Bachilo, U. Rempel, C. von Borczyskowski, Opt. Spectrosc. 83 (1997) 597-606.

[47] U. Rempel, S. Meyer, B. von Maltzan, B. von Borczyskowski, J. Lumin. 78 (1998) 97-110.

[48] V.N. Knyukshto, E.I. Zenkevich, E.I. Sagun, A.M. Shulga, S.M. Bachilo, Chem. Phys. Lett. 304 (1999) 155-156.

[49] H. Tamiaki, T. Miyatake, R. Tanikaga, A.R. Holzwarth, K. Schaffner, Book of Abstract of the XYI IUPAC Symposium on Photochemistry, 1996, pp. 41-42, Helsinki, Finland.

[50] J.L. Sessler, M.K. Johnson, S.E. Creager, J.C. Fettinger, J.A. Ibers, J. Am. Soc. 112 (1990) 9310-9329.

[51] M.R. Wasielewski, Chem. Rev. 92 (1992) 435-462.

[52] J.M. Graziano, P.A. Liddell, L. Leggett, A.L. Moore, T.A. Moore, D. Gust, J. Phys. Chem. 98 (1994) 1758-1761.

[53] N. Ohta, Y. Iwaki, T. Ito, I. Yamazaki, A. Osuka, J. Phys. Chem. B 103 (1999) 11242-11245.

[54] J. Rodriguez, C. Kirmaier, D. Holton, J. Am. Chem. Soc. 111 (1989) $6500-6506$

[55] R.A. Marcus, Rev. Modern Phys. 65 (1993) 599-610.

[56] S.L. Murrov, I. Carmichael, G.L. Hug, Handbook of Photochemistry, Marcel Deccer, New York, 1993, pp. 269-278.

[57] E.I. Zenkevich, D.S. Kilin, A. Willert, S.M. Bachilo, A.M. Shulga, U. Rempel, C. von Borczyskowski, Mol. Cryst. Liq. Cryst. 362 (2000) (in press).

[58] P. Reineker, Springer Tracts in Modern Physics, vol. 94, Springer, Berlin, 1982, p. 111

[59] P. Herman, I. Barvik, Phys. Rev. B 48 (1993) 3130-3137.

[60] M. Schreiber, D. Kilin, U. Kleinekathoefer, J. Lumin. 83-84 (1999) 235-240.

[61] A. Weller, Z. Phys. Chem. Neue Folge 133 (1982) 93-97.

[62] P. Supan, J. Chem. Soc. Farad. Trans. I 83 (1987) 495-499.

[63] G.J. Kavarnos, N.J. Turro, Chem. Rev. 86 (1986) 401-409.

[64] J.-H. Fuhrhop, K.M. Kadish, D.G. Davis, J. Am. Chem. Soc. 95 (1973) 5140.

[65] D. Dolphin (Ed.), The Porphyrins, vol. V, Academic Press, New York, 1978.

[66] P. Worthington, P. Hambright, R. Williams et al., J. Inorg. Biochem. 12 (1980) 281

[67] D. Gust, T.A. Moore, A.L. Moore, C. Devados, P.A. Liddell, R. Hermant, R.A. Nieman, L.G. Demanche, J.M. DeGraziano, I. Gouni, J. Am. Chem. Soc. 114 (1992) 3590.

[68] M.R. Wasielewski, D.G. Johnson, M.P. Niemczyk, G.L. Gains III, M.P. O'Neil, W.A. Svec, J. Am. Chem. Soc. 112 (1990) 6482-6488. 